\title{
Modulation of Daily Rainfall in Southern Vietnam by the Madden-Julian Oscillation and Convectively Coupled Equatorial Waves ${ }^{0}$
}

\author{
RODERICK VAN DER LINDEN \\ Institute for Geophysics and Meteorology, University of Cologne, Cologne, Germany \\ ANDREAS H. FINK \\ Institute of Meteorology and Climate Research, Karlsruhe Institute of Technology, Karlsruhe, Germany \\ JOAQUIM G. PINTO \\ Department of Meteorology, University of Reading, Reading, United Kingdom, and Institute for Geophysics and \\ Meteorology, University of Cologne, Cologne, Germany \\ TAN PHAN-VAN \\ Department of Meteorology, Hanoi University of Science, Vietnam National University, Hanoi, Vietnam \\ GEORGE N. KILADIS \\ Physical Sciences Division, NOAA/Earth System Research Laboratory, Boulder, Colorado
}

(Manuscript received 21 December 2015, in final form 6 May 2016)

\begin{abstract}
Rainfall extremes have a large socioeconomic relevance for southern Vietnam. More than 30 million people live in this low-lying, flood-prone region in Southeast Asia. In this study the influence of the Madden-Julian oscillation (MJO) and convectively coupled equatorial waves on the modulation of daily rainfall during the rainy season (May-October) is evaluated and quantified using an extensive station database and the gridded Asian Precipitation-Highly Resolved Observational Data Integration Toward Evaluation of Water Resources (APHRODITE) product for different phases of the equatorial waves.

The MJO, Kelvin, and equatorial Rossby (ER) waves significantly modulate daily rainfall in Vietnam south of $16^{\circ} \mathrm{N}$. The MJO shows the most coherent signals across the region, followed by ER waves, whose influence is strongest in central Vietnam; Kelvin waves only affect the southern parts of Vietnam. For all waves, the frequency of occurrence of intense daily rainfall larger than $25 \mathrm{~mm}$ is significantly enhanced during wet phases, whereas the magnitude of rainfall anomalies is related to the wave's amplitude only in the MJO and ER cases. A novel wave interference diagram reveals strong positive interferences of dry and wet anomalies when the MJO occurs concurrently with Kelvin and ER waves. In terms of causes of rainfall anomalies, the waves modulate tropospheric moisture convergence over the region, but a strong influence on the depth of the monsoon flow and the vertical wind shear is discernible from radiosonde data only for the MJO. The results suggest new opportunities for submonthly prediction of dry and wet spells in Indochina.
\end{abstract}

Supplemental information related to this paper is available at the Journals Online website: http://dx.doi.org/10.1175/ JCLI-D-15-0911.s1.

Corresponding author address: Roderick van der Linden, Institute for Geophysics and Meteorology, University of Cologne, Pohligstr. 3, 50969 Cologne, Germany.

E-mail: rvdlinde@uni-koeln.de

\section{Introduction}

Vietnam is located at the eastern side of the Indochina Peninsula bordering the South China Sea (SCS) and is characterized by a $1650-\mathrm{km}$ north-south extension from the Tropic of Cancer (about $23.25^{\circ} \mathrm{N}$ ) to the deep tropics at around $8.5^{\circ} \mathrm{N}$. While mountain landscapes are found at the northern border with China and in central Vietnam, parts of northern and southern 
Vietnam are characterized by the extensive and heavily populated floodplains and deltas of the Red and Mekong Rivers. The present study focuses on the southern part of Vietnam (south of $16^{\circ} \mathrm{N}$ ), comprising the Vietnamese Central Highlands and the Mekong River delta region (Fig. 1). Because of its geographic location, the seasonal climate of Vietnam is dominated by the IndoAsian monsoon system (Wang 2006). Except in the South Central Coast region (Fig. 1), where a boreal fall rainfall maximum is observed, the remaining part of the study region has a rainy season between May and October, peaking in August (Yen et al. 2011; Nguyen et al. 2014). The rainy season provides more than $80 \%$ of annual rainfall in the study region (Nguyen et al. 2014). While the Mekong delta is one of the two major ricegrowing regions of Vietnam and a hot spot of aquaculture production, the central highland is the main coffee growing region in Vietnam (General Statistics Office of Vietnam 2016). Given the agricultural practices, forecasting of the rainy season onset and of dry and wet spells within the monsoon season has a clear socioeconomic value. This potential value increased in recent years, since rainfall extremes during the monsoon increasingly endanger existing and planned industrial zones in the low-lying, flood-prone areas of southern Vietnam (Asian Development Bank 2010), which has a population of more than 32 million. Finally, Vietnam's power supply relies heavily on hydroelectricity (U.S. Energy Information Administration 2015).

Predictability of monsoonal dry and wet spells on weekly time scales in Vietnam is potentially related to the Madden-Julian oscillation (MJO; Madden and Julian 1971, 1972) and convectively coupled equatorial waves (CCEWs; Kiladis et al. 2009). The MJO and CCEWs are well-known phenomena that account for large fractions of intraseasonal and synoptic-scale tropical convective and rainfall variability (Zhang 2005; Kiladis et al. 2009, and references therein). For the region under study, Straub et al. (2006) and Tong et al. (2009) showed that Kelvin waves, which are one important type of CCEW, along with the MJO, also impact the onset of the SCS summer monsoon. The practical forecast limits of the MJO have recently been pushed to about two weeks (Zhang and van den Dool 2012; Saha et al. 2014). To exploit this predictability, the impact of convectively active and wet phases of the MJO and CCEWs on daily rainfall variability at regional scales needs to be quantified and understood. To describe the wave-related in situ rainfall variability and impact on surface hydrology, multidecadal time series from dense rain gauge network data or gridded products derived from these datasets are the preferred source, though such datasets are rare in the tropics. Nonetheless, some

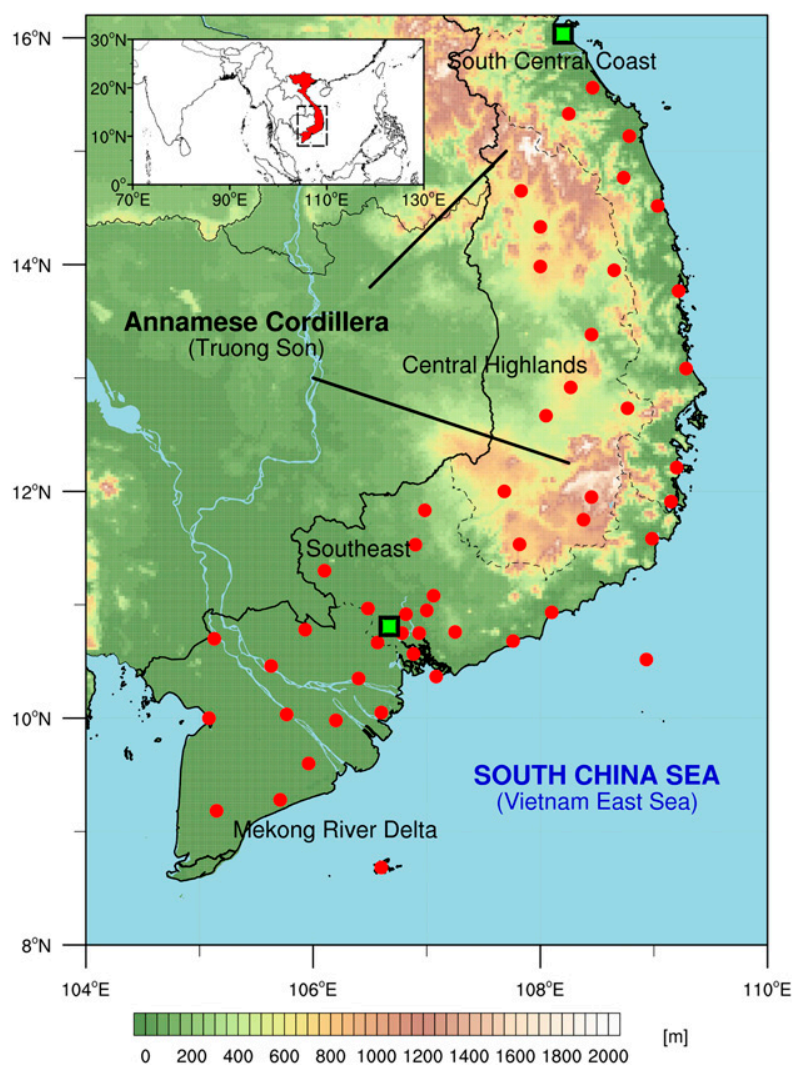

FIG. 1. Topographic map of the study area. Names denote different regions of Vietnam, which are separated with dashed lines. Rainfall stations used in the analysis are indicated with red dots. The green squares show the locations of the rainfall and radiosonde station in Ho Chi Minh City (Southeast) and of the radiosonde station in Da Nang (South Central Coast).

studies identified an influence of the MJO on regional rainfall based on rain gauge measurements: Wheeler and Hendon (2004) found an increase in the probability of extreme rainfall in Australia during convectively active phases of the MJO, Matthews and Li (2005) detected spatially coherent rainfall anomalies in the western Pacific during dry and wet phases of the MJO, and Pohl and Camberlin (2006) provided evidence of the influence of the MJO on rainfall in Kenya and northern Tanzania. As another example, Pohl et al. (2009) investigated the influence of the MJO on rainfall in West Africa and found an asymmetric response in the western Sahel, with the convectively suppressed phase showing a stronger signal in the rain gauge data.

In addition to these statistical relationships, it is necessary to understand how the phases of the MJO and CCEWs change the (thermo-)dynamic environment that favors certain types of convective systems. Yasunaga and Mapes (2012) have shown that the influences of the MJO and CCEWs occur on different spatial and temporal scales, from scattered convection 
and small-scale precipitation systems to mesoscale convective systems and stratiform rain. Employing Tropical Rainfall Measurement Mission (TRMM) rainfall data, they found that CCEWs modulate rainfall in a variety of ways: the more divergent Kelvin and inertio-gravity waves tend to influence mesoscale convective systems and stratiform rain, while more rotational equatorial Rossby (ER), mixed Rossby-gravity (MRG) waves, and tropical depression-type (easterly wave) disturbances rather influence rainfall of the convective type and smaller-sized rainfall systems. On the other hand, they demonstrated that the MJO exhibits precipitation modification features of both divergent and rotational waves. The region under study is strongly influenced by propagating organized mesoscale convective systems (MCSs) during boreal summer (Roca et al. 2014; Houze et al. 2015). The former study found, for example, that the fraction of rainfall from MCSs propagating more than $250 \mathrm{~km}$ exceeds $50 \%$ over the Indochina Peninsula. Thus, it seems obvious to study the MJO- and CCEW-related changes to the synoptic-scale environment in which the MCSs form.

While Wheeler and Kiladis (1999) focused on Southern and Northern Hemisphere summer seasons, Roundy and Frank (2004a) showed the importance of different waves relative to the overall regional variability of convection for all four seasons. To demonstrate their importance, the latter authors created climatologies of wave-filtered variances for a 10 -yr period by application of wavenumber-frequency filters to outgoing longwave radiation (OLR) and precipitable water data in the space-time domains of several CCEWs. They found that the relative contributions of eastward-propagating parts of the intraseasonal oscillation, which includes the MJO, and westward-propagating ER waves are more pronounced over the global tropics than other modes. They also stress that waves interact with and suppress or enhance regional convection, instead of exclusively forcing convective signals to follow their large-scale divergence patterns. Several studies have demonstrated that different wave modes do not necessarily occur in isolation but can occur concurrently and also interact (e.g., Straub and Kiladis 2003; Masunaga 2007; Roundy 2008; Masunaga 2009). Yasunaga and Mapes (2012) found that the activity of the (in their notation) divergent waves is enhanced in the developing phase of the MJO, whereas an enhancement of the activity of rotational waves preferentially occurs in the decaying phase of the MJO.

In addition to studies with a global perspective on tropical wave activity (e.g., Wheeler et al. 2000; Lubis and Jacobi 2015), several studies focused on the Maritime Continent and western Pacific regions. However, these studies focused on different seasons, did not include Vietnam in their analysis, did not take into account a variety of tropical waves, and/or evaluated the influence of tropical waves only for a short period (e.g., Wheeler and Hendon 2004; Matthews and Li 2005; Wu et al. 2012; Matthews et al. 2013; Xavier et al. 2014). Yokoi et al. (2007) included Vietnam in their analysis of intraseasonal rainfall variability over the Indochina Peninsula, but they did not use a wavenumberfrequency filter and did not differentiate between convectively active and inactive phases.

In this study, the influence of various large-scale equatorial waves on intraseasonal rainfall variability over southern Vietnam during the rainy seasons from May to October 1979-2012 is investigated and quantified for the first time using an extensive database of rain gauge measurements and gridded datasets. This includes the effects of wave interference and phase-dependent changes of the waves to the synoptic-scale (thermo-) dynamic environment. Data and methods are described in section 2. The modulating influence of the MJO and CCEWs on rainfall and dynamical fields in southern Vietnam is discussed in section 3. The results are summarized and discussed in section 4.

\section{Data and methods}

Satellite-observed OLR is frequently used as a proxy for deep convection in the tropics (e.g., Arkin and Ardanuy 1989, and references therein) and, more specifically, for the detection of tropical intraseasonal variability of convection (e.g., Wheeler and Kiladis 1999). Therefore, tropical wave activity was analyzed in this study for the period 1979-2012 using $2.5^{\circ} \times 2.5^{\circ}$ daily NOAA Interpolated OLR data (Liebmann and Smith 1996). To quantify the rainfall-modulating effects of the MJO and CCEWs, daily rainfall data from the gridded Asian Precipitation-Highly Resolved Observational Data Integration Toward Evaluation of Water Resources (APHRODITE) Monsoon Asia V1101 dataset (Yatagai et al. 2012) were used for the period 1979-2007. APHRODITE data are available in $0.25^{\circ} \times 0.25^{\circ}$ horizontal resolution and are based on rain gauge measurements. In addition, daily rainfall measurements from stations operated by the Vietnamese National HydroMeteorological Service (NHMS; NHMS 2014, unpublished data) for the period 1979-2012 were analyzed (Fig. 1, Table S1). Only stations south of $16^{\circ} \mathrm{N}$ and with at least $90 \%$ data availability were considered. The accumulation period of daily APHRODITE and station data is 1200-1200 UTC [i.e., 1900-1900 local time (LT)]. Even though APHRODITE used station data, gridding inevitably causes smoothing of extremes; thus, the analysis 
of the dense station network has two advantages: (i) in situ observations preserve topographic rainfall gradients (cf. supplemental material); and (ii) absolute threshold-based extreme value statistics can be applied. Moreover, it is very likely that some stations have not entered the APHRODITE analysis. The waves' effects on the dynamical fields were quantified using horizontal wind components on the 850-hPa pressure level from the 6-hourly ERA-Interim at $0.75^{\circ} \times 0.75^{\circ}$ latitude-longitude resolution (Dee et al. 2011). Daily values were calculated by averaging over 0000, 0600,1200, and 1800 UTC analysis times. Additionally, vertical profiles of the atmosphere from the Integrated Global Radiosonde Archive (IGRA; Durre et al. 2006) for the stations Ho Chi Minh City (WMO station ID 48900; $10^{\circ} 49^{\prime} \mathrm{N}$, $106^{\circ} 40^{\prime} \mathrm{E}$ ) and Da Nang (WMO station ID 48855; $16^{\circ} 2^{\prime} \mathrm{N}, 108^{\circ} 11^{\prime} \mathrm{E}$ ) were analyzed for the period 1979 2012. For the analysis, zonal and meridional wind components from IGRA were linearly interpolated to every $50 \mathrm{hPa}$ between the 1000- and $100-\mathrm{hPa}$ pressure levels, and specific humidity was calculated from vertically interpolated temperatures and dewpoint temperatures. Only 0000 UTC (0700 LT) profiles were used to avoid impacts on low-level wind profiles by turbulence in the daytime boundary layer. Radiosonde data were available for about $45 \%-57 \%$ of all wave cases, depending on the radiosonde station and the wave phase. The ECMWF four-dimensional variational data assimilation (4D-Var) system assimilates radiosonde wind and humidity data when available. However, when compared to ERA-Interim-derived profiles, the radiosonde profiles are in situ measurements, and effects of data assimilation or dates with missing radiosonde data are excluded.

There are various approaches for the global determination of $\mathrm{MJO}$ phases based on circulation-only indices [velocity potential MJO (VPM) index (Ventrice et al. 2013)], circulation and convection indices [realtime multivariate MJO (RMM) index (Wheeler and Hendon 2004)], or convection-only indices [OLR-based MJO index (OMI) (Kiladis et al. 2014)]. However, for consistency reasons and to investigate the effects of concurrent occurrences of convectively active phases of multiple waves, different phases of tropical wave activity were determined regionally following the method originally proposed by Riley et al. (2011) to determine the MJO phases. Yasunaga and Mapes (2012) applied this method to TRMM data to determine the phases and amplitudes of the MJO and CCEWs. Here, the method was applied to OLR data averaged between $7.5^{\circ}$ and $12.5^{\circ} \mathrm{N}$; the longitude for which the phases were determined was $107.5^{\circ} \mathrm{E}$. The method is exemplified for the $\mathrm{MJO}$ in Fig. 2. The time series of standardized wave-filtered OLR and its standardized temporal change (tendency) centered at $107.5^{\circ} \mathrm{E}$ are calculated for MayOctober 1984 to construct the phase diagram in Fig. 2c. The time series for both quantities can be inferred from the rectangles at $107.5^{\circ} \mathrm{E}$ in the Hovmöller diagrams of Figs. 2a and 2b. The color filling of the circles in Fig. 2c corresponds to the color coding of the standardized wave-filtered OLR in Fig. 2a; positive values (red markers) indicate that regional convection is suppressed by the equatorial wave, whereas negative values (blue markers) indicate regionally enhanced convection. In Fig. 2c, one complete cycle of the MJO is highlighted; it starts with phase 7 and passes first through phases of suppressed convection and then through phases of enhanced convection in clockwise direction. Note that the starting and end points of this complete MJO cycle are marked with green markers and that values outside the highlighted period and region are shown in grayscale.

In terms of the interpretation of the phase diagram, phase 1 is the driest phase, since standardized wavefiltered OLR is at maximum, and its tendency is small or changing from positive to negative. Vice versa, phase 5 is the wettest phase, since standardized wave-filtered OLR is at minimum, and its tendency is small or changing from negative to positive. In phases 3 and 7, the sign of standardized wave-filtered OLR changes from positive to negative and back from negative to positive, respectively. Hence, these phases are in the following referred to as transition phases. The amplitude of waves is the distance from the origin of the phase diagram. Only waves with amplitudes greater than one (i.e., only circles outside the gray-shaded unity circle in Fig. 2c) are considered. OLR data were filtered in the wavenumberfrequency domains of the MJO and two types of CCEWs-namely, Kelvin waves and $n=1$ ER wavesby using the canonical wavenumber-frequency filter after Wheeler and Kiladis (1999). Potential effects of Doppler shifting by the basic-state zonal flow are deemed to be relatively small over the region (Dias and Kiladis 2014) and are already taken into account by filtering for the observed spectral peaks of the selected wavenumber-frequency domains. In the following, $n=$ 1 ER waves are referred to as ER waves.

Note that MJO phases obtained from the VPM, RMM, and OMI indices assign convectively active regions on the globe, whereas the method of Riley et al. (2011) defines phases locally (i.e., phases from global and regional methods are not equivalent). However, during May-October, during $84 \%-99 \%$ of days when amplitudes of global and regional indices are concurrently greater than one, the regional index is in phases 3-7 (i.e., wet phases 4-6 and transition phases 3 and 7) when the global indices are in phases $4-6$ (i.e., the 


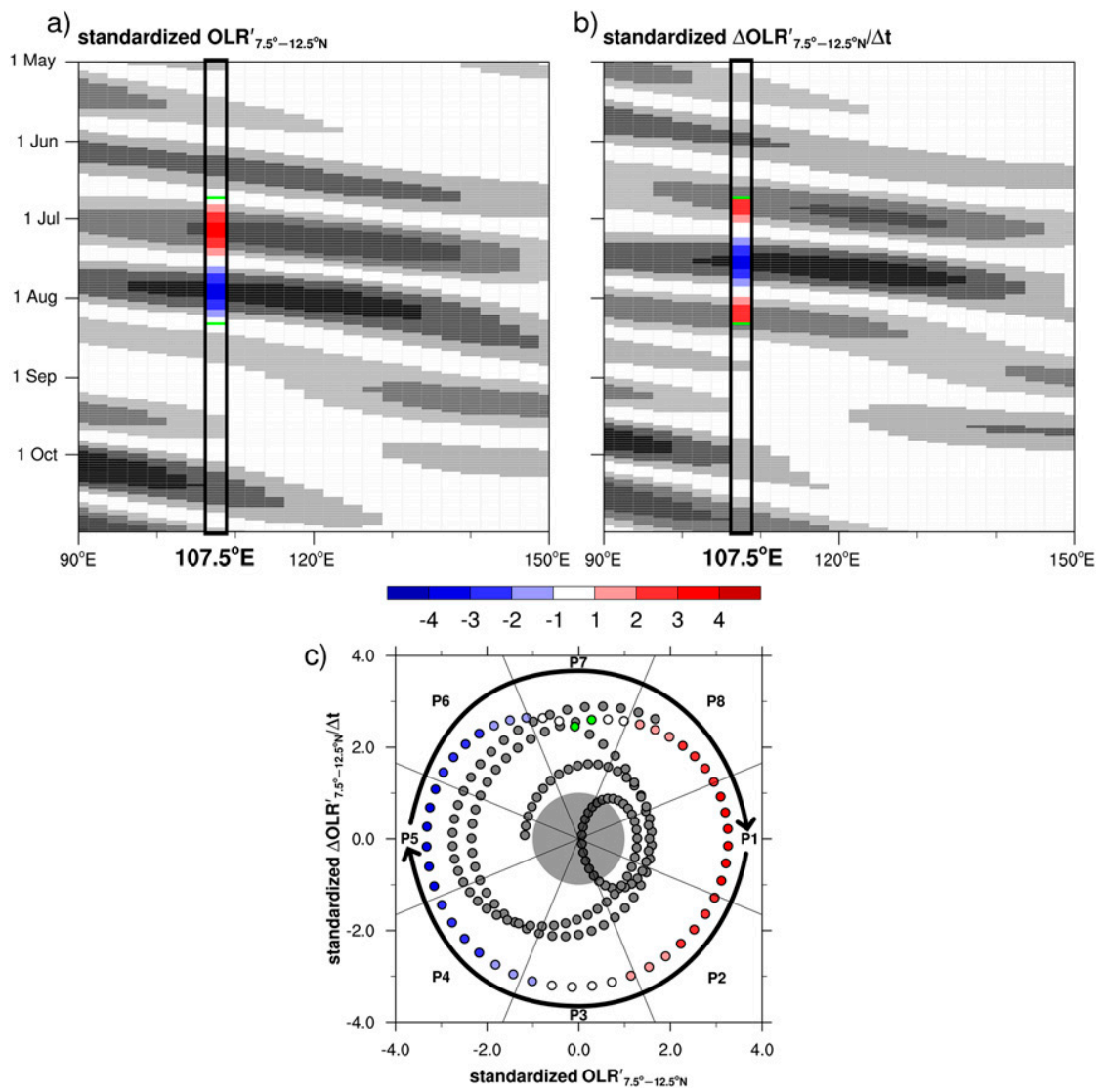

FIG. 2. Illustration of the method to determine the local phase of the MJO or any CCEW proposed by Yasunaga and Mapes (2012). (a) Standardized wave-filtered OLR, (b) tendency of standardized wave-filtered OLR, and (c) phase diagram constructed from (a) and (b). The example is based on MJO-filtered OLR that was averaged between $7.5^{\circ}$ and $12.5^{\circ} \mathrm{N}$ for MayOctober 1984. The local phase is determined for the longitude $107.5^{\circ} \mathrm{E}$ centered on Vietnam, as indicated by the rectangle. The color bar shows standardized values (no units). Color filling of the circles in (c) corresponds to the color coding of the standardized wave-filtered OLR in the rectangle of (a). For more details, see section 2.

convective envelope of the $\mathrm{MJO}$ is located in the Maritime Continent and western Pacific regions). Even though the commonly used latitude sector for wavenumber-frequency filtering is $15^{\circ} \mathrm{S}-15^{\circ} \mathrm{N}$ (e.g., Wheeler and Kiladis 1999$), 7.5^{\circ}-12.5^{\circ} \mathrm{N}$ was chosen here to enhance the focus on southern Vietnam. A comparison of phases with amplitudes greater than one determined for both sectors showed an agreement of more than $80 \%$ of phases with a maximum of one phase difference for the period May to October (not shown), thus justifying the use of the $7.5^{\circ}-12.5^{\circ} \mathrm{N}$ sector.

Daily time series of wave phases and amplitudes were then used to calculate composite anomalies of rainfall and horizontal wind components for each wave phase. In these composites, any influence of other wave types that occur on the same days with an amplitude greater than one has not been filtered out. Daily anomalies of wind components were calculated from a daily climatology, whereas daily rainfall anomalies were calculated relative to the average daily rainfall in the pentad centered about the date of a certain phase. The statistical significance of anomalies was tested with the distribution-independent bootstrap method with 10000 samples. Note that the statistical significance of wind vectors was only tested for the zonal wind component, because the zonal wind exhibits stronger anomalies when compared with the meridional wind component. Anomalies significant at the 5\% level are highlighted. Hereafter, the notations "statistically significant" and "significant" are used interchangeably.

\section{Modulation of rainfall by large-scale equatorial waves}

Visual inspection of regional power spectra after Dias and Kiladis (2014) centered about $90^{\circ}$ E suggests that the 

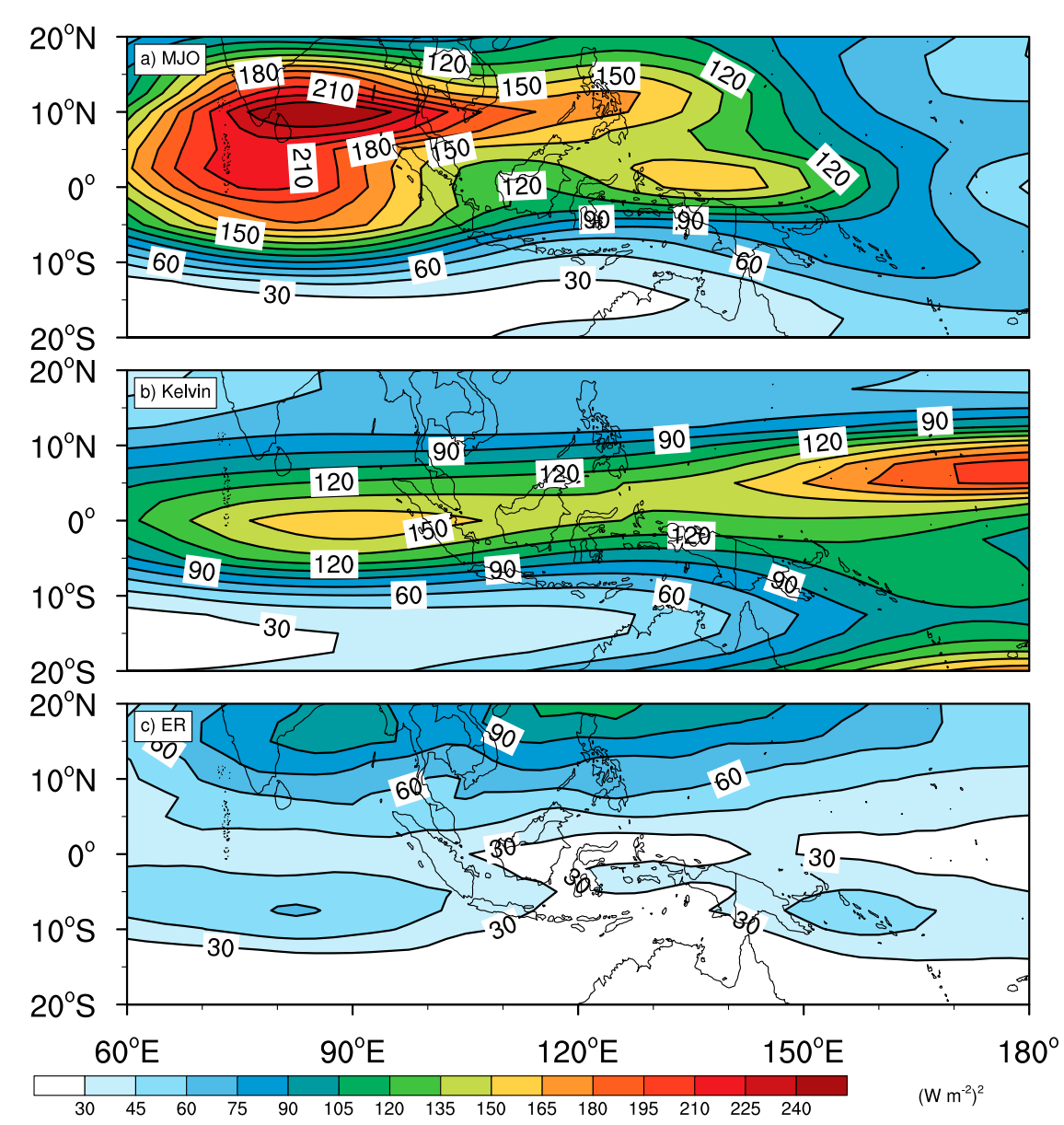

FIG. 3. Wave-filtered daily OLR variance for (a) the Madden-Julian oscillation, (b) Kelvin waves, and (c) equatorial Rossby waves during May-October.

most relevant CCEWs in southern Vietnam are Kelvin and ER waves. This assumption is corroborated by wavenumber-frequency-filtered OLR variances by Wheeler and Kiladis (1999) and Roundy and Frank (2004a). These studies, together with Zhang and Dong (2004) and Fig. 3 also stress the relevance of the MJO for intraseasonal rainfall variability in southern Vietnam. Filtering for higher-frequency waves-namely, $n=1$ and $n=2$ westward inertio-gravity (WIG) waves-was not feasible because of the use of daily OLR values. However, Wheeler and Kiladis (1999) have shown that WIG waves are mostly constrained to regions closer to the equator, and regional power spectra of Dias and Kiladis (2014) indicate that WIG waves do not play a dominant role in the longitude sector centered about $90^{\circ} \mathrm{E}$. In addition, influence of MRG and eastward inertio-gravity (EIG) waves was tested but found to be weak in southern Vietnam (not shown). This is consistent with recent findings of Kiladis et al. (2016) and Dias and Kiladis (2016), who showed that convectively coupled MRG and EIG waves occur predominantly in the western/central Pacific Ocean. In the following subsections, the impact of each type of the relevant waves on rainfall in southern Vietnam is discussed. Wave phases 4-6 (1-2 and 8) are termed wet (dry) phases throughout all types of waves discussed, because in, for example, wave-filtered OLR maps, large-scale regions of enhanced (suppressed) deep convection are discernible in the equatorial belt during these phases. Phases 3 and 7 are termed transitional phases, the former from dry to wet, the latter from wet to dry.

\section{a. Madden-Julian oscillation}

The highest MJO-filtered OLR daily variance (hereafter simply referred to as variance) in the Indian Ocean and western Pacific regions during May to October occurs over the Indian Ocean (Fig. 3a), where the MJO is most frequently initiated (e.g., Seo and Kim 2003; Zhang 2005). The extension of high-variance values south and southwestward of India can be attributed to the seasonal transition: namely, a northward movement of the MJO between boreal spring and boreal summer [cf. seasonal 

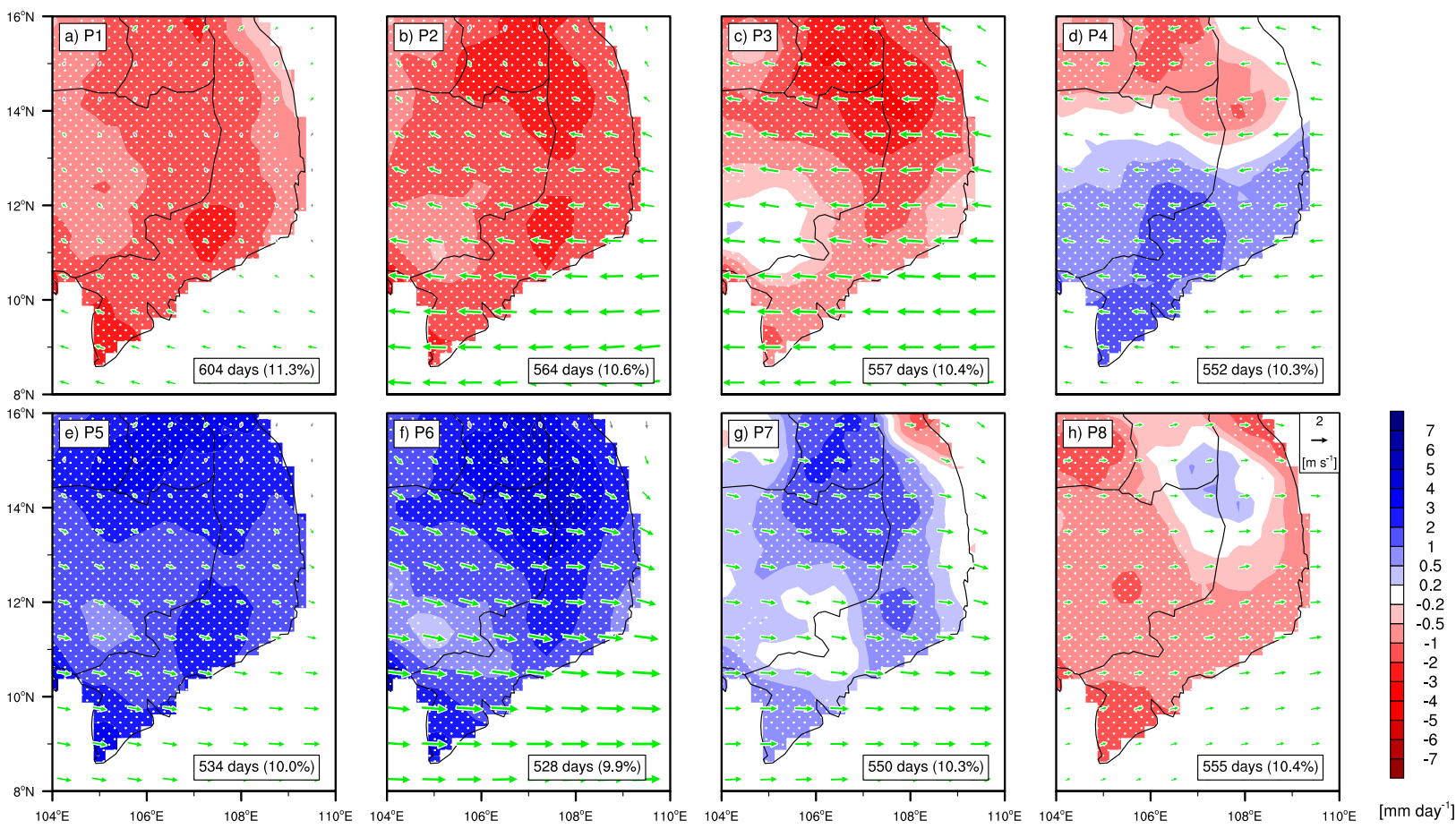

FIG. 4. Anomalies of APHRODITE rainfall (colors) and ERA-Interim 850-hPa wind (vectors) per phase of the Madden-Julian oscillation (P1-P8) during May-October. Stippled areas and green vectors indicate statistically significant anomalies. The numbers in the bottom-right corners indicate the frequency of days with amplitude greater than one in a certain phase. (h) The reference vector for ERAInterim wind.

OLR variances in Roundy and Frank (2004a)]. In Vietnam, the highest variance occurs at the southern tip of the country and exhibits a strong northward decrease. However, it is only about half of the MJO variance observed in the peak region in the southern Bay of Bengal.

The MJO exhibits the strongest signals in rainfall and low-level wind anomalies (Figs. 4, 5, 6a) when compared with the other waves considered here. Figures 4 and 5 show for each of the eight MJO phases the variation of APHRODITE and station rainfall anomalies, respectively, which are overlaid with 850 -hPa vector wind anomalies. Figure 6 shows phase-dependent rainfall anomalies along a south-north station transect. Generally, there is a good agreement between APHRODITE and station data when comparing rainfall anomalies from both datasets for the MJO (cf. Figs. 4, 5), which points to a regional-scale and coherent influence of the MJO. Considering all dry phases, statistically significant APHRODITE anomalies are most widespread in phase 2 over southern Vietnam and adjacent regions (cf. Figs. 4a, 4b, and 4h). This distinction of phase 2 relative to the other dry phases can also be observed for station anomalies (cf. Figs. 5a, 5b, and 5h). There are only four stations in that phase (located at the coast and mostly north of approximately $12^{\circ} \mathrm{N}$ ), which show nonsignificant rainfall anomalies (Figs. 5b, 6a, Table S2).
During dry phases, station rainfall is suppressed by about $20 \%-27 \%$ in relation to the long-term mean daily rainfall (cf. Figs. 5 and S1, Tables S1 and S2). In phase 3, rainfall anomalies are still predominantly negative (Figs. 5c, 6a). However, especially for station measurements, anomalies are no longer significant at some locations in this phase. Phases $1-4$ show $850-\mathrm{hPa}$ easterly wind anomalies (Figs. 5a-d). In these phases, wind anomalies on the western side of the Annamese Cordillera (Fig. 1), also denominated the Truong Son Mountains in Vietnam, are generally weaker yet significant. The strongest easterly wind anomalies occur in phase 3 and are most pronounced toward the south (Fig. 5c).

In phase 4, rainfall anomalies have turned from negative to positive south of about $13.5^{\circ} \mathrm{N}$ (Figs. $4 \mathrm{~d}, 5 \mathrm{~d}$ ), and in phase 5 the whole region shows significant positive rainfall anomalies of up to $6 \mathrm{~mm}_{\text {day }}{ }^{-1}$ (Figs. $4 \mathrm{e}, 5 \mathrm{e}, 6 \mathrm{a}$ ). On average, anomalies during wet MJO phases correspond to an increase of approximately $22 \%-34 \%$ in relation to the long-term mean daily station rainfall (cf. Figs. 5 and S1, Tables S1 and S2). The northward extension of rainfall anomalies is in agreement with the northward propagation of the MJO by interaction with the Maritime Continent, as demonstrated, for example, by Zhu et al. (2010). Additionally, the moist monsoon 

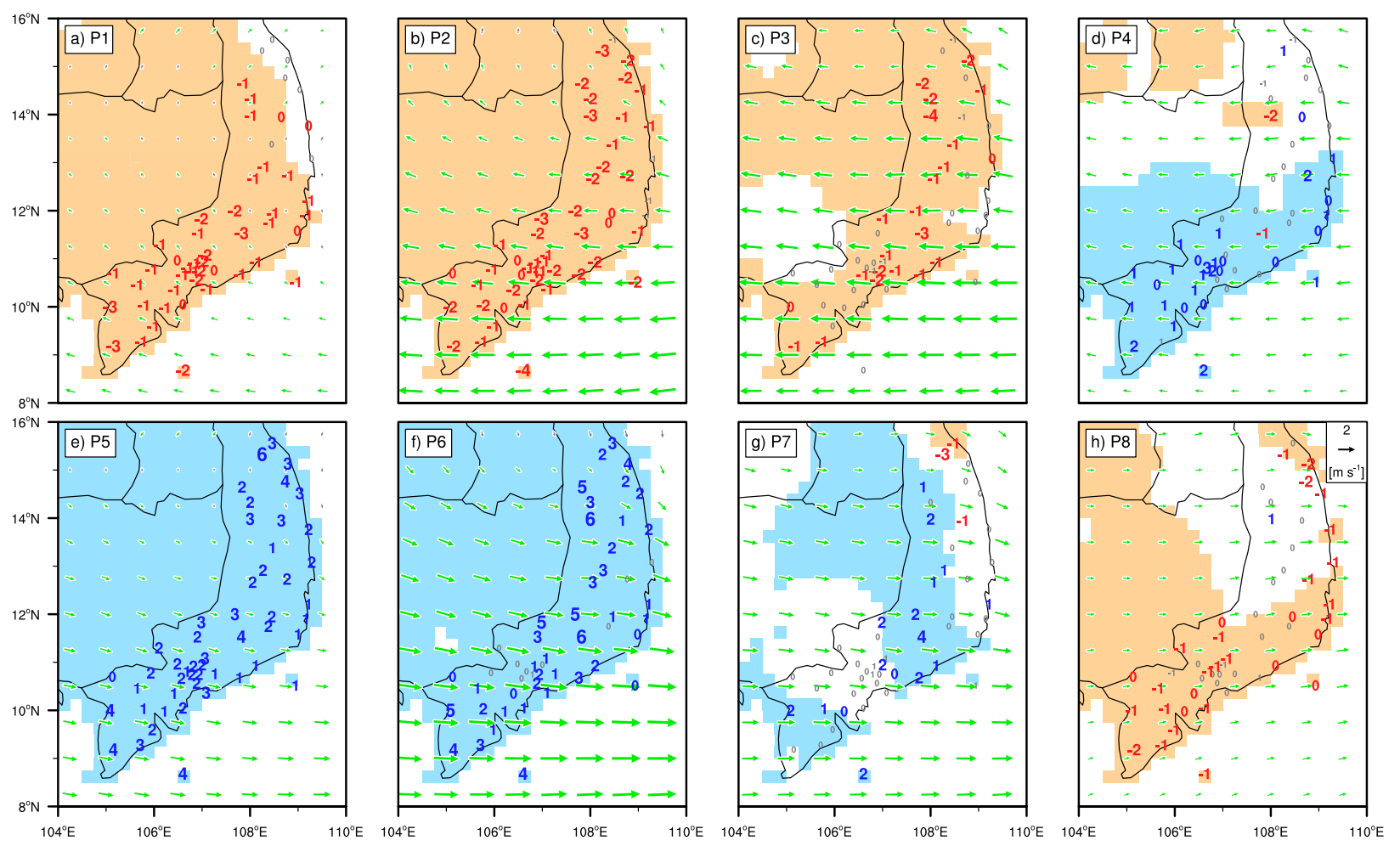

FIG. 5. Anomalies of station rainfall (numbers; $\mathrm{mm} \mathrm{day}^{-1}$ ) and ERA-Interim 850-hPa wind (vectors) per phase of the Madden-Julian oscillation (P1-P8) during May-October. Font sizes of numbers increase with the magnitude of rainfall anomalies. Colored numbers and green vectors indicate statistically significant anomalies. Light blue (light orange) shaded areas indicate regions of statistically significant wet (dry) APHRODITE rainfall anomalies (see Fig. 4). (h) The reference vector for ERA-Interim wind.

layer has already started to deepen in phase 4 , as can be seen from deepening low-level westerlies in the composite vertical profile from Ho Chi Minh City (Fig. 7a). From phase 4 to 5, 850-hPa anomalous winds in southern Vietnam turn from significantly easterly to westerly and stay westerly in phases 6-8 (Figs. 5e-h). As expected, vectors of moisture flux between the surface and $500 \mathrm{hPa}$ show a similar turn (Fig. S2). However, significant convergence of moisture fluxes in this layer, which contains nearly $90 \%$ of the columnar moisture, already starts in phase 3 during weakening easterly anomalies. The highest positive rainfall anomalies occur in phase 6 especially on the windward side of the Annamese Cordillera from about $13^{\circ} \mathrm{N}$ northward and also reach up to about $6 \mathrm{~mm} \mathrm{day}^{-1}$ (Figs. 4f, 5f). A similar but slightly weaker effect is also discernible in phases 5,7 , and 8 . Thus, low-level westerly wind anomalies associated with the MJO seem to enhance orographic rainfall on the windward side of the Annamese Cordillera, whereas easterly anomalies do not show orographically enhanced rainfall on its eastern side. This finding is related to the fact that the total flow across the mountains remains westerly in all phases. While rainfall anomalies are predominantly negative in phase 3 , anomalies are mostly positive in transition phase 7 , although anomalies are not all statistically significant (Figs. 4g, 5g, 6a). As a consequence, moisture flux convergence anomalies seem to lead rainfall anomalies by about one phase because southern Vietnam is already dominated by significant moisture flux divergence anomalies in phase 7 (Fig. S2). Overall, the frequency of occurrence of different phases, as indicated in the inset boxes in the bottom-right corners of the panels in Fig. 4, does not strongly vary. This invariance is also observed for Kelvin and ER waves (Figs. 9, 11).

The mean vertical profiles of horizontal winds in Ho Chi Minh City per MJO phase reveal that not only lowlevel winds are modulated by different phases, but also their vertical profiles (Fig. 7a). After phase 3, when the minimum vertical extent of westerly winds is reached with predominantly westerly winds between the surface and approximately $850 \mathrm{hPa}$, the depth of the monsoonal westerlies strongly increases. In phase 6 , the maximum depth is reached when westerly winds prevail between the surface and about $500 \mathrm{hPa}$ and have also strengthened throughout this layer with peak velocities of $10 \mathrm{~m} \mathrm{~s}^{-1}$ in the $900-800-\mathrm{hPa}$ layer. This deep moist monsoon flow favors outbreaks of convection but also 
a) MJO

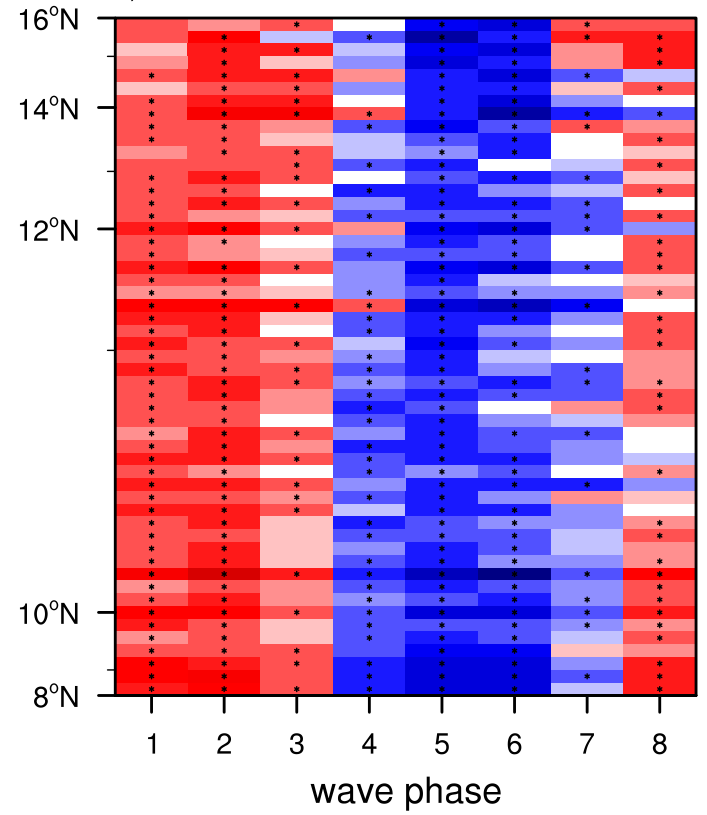

b) Kelvin

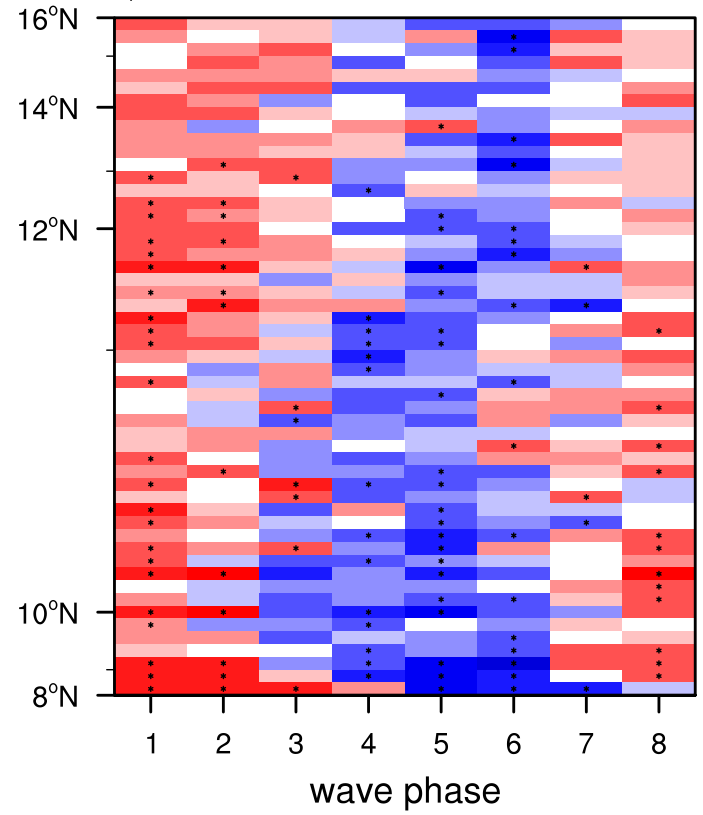

c) ER

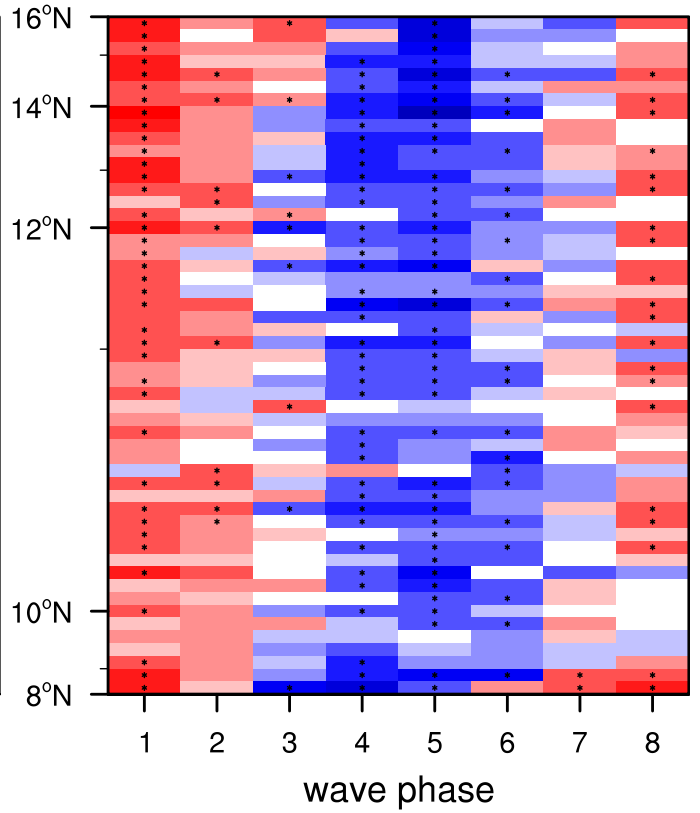

$165 \times 3,2 \times 0,0 ? 0 ? 5 \times 23 \times 561 \quad\left[\mathrm{~mm} \mathrm{day}^{-1}\right]$

FIG. 6. Station rainfall anomalies per wave phase during May-October for the (a) Madden-Julian oscillation, (b) Kelvin waves, and (c) equatorial Rossby waves. Asterisks indicate statistically significant anomalies. Note that the vertical axis showing latitude is not linear but depends on the number of stations between latitude bands.

provides strong lower-tropospheric wind shear, providing favorable conditions for the organization of convection on different horizontal scales (e.g., Anber et al. 2014 and references therein). In phases 5-8, zonal winds are anomalously westerly between the surface and about $400 \mathrm{hPa}$ and anomalously easterly in upper levels, whereas these patterns of wind anomalies are reversed in phases 1-4. In other words, the wettest MJO phases are preceded by easterly wind anomalies between the surface and about $400 \mathrm{hPa}$, while the driest phases are 

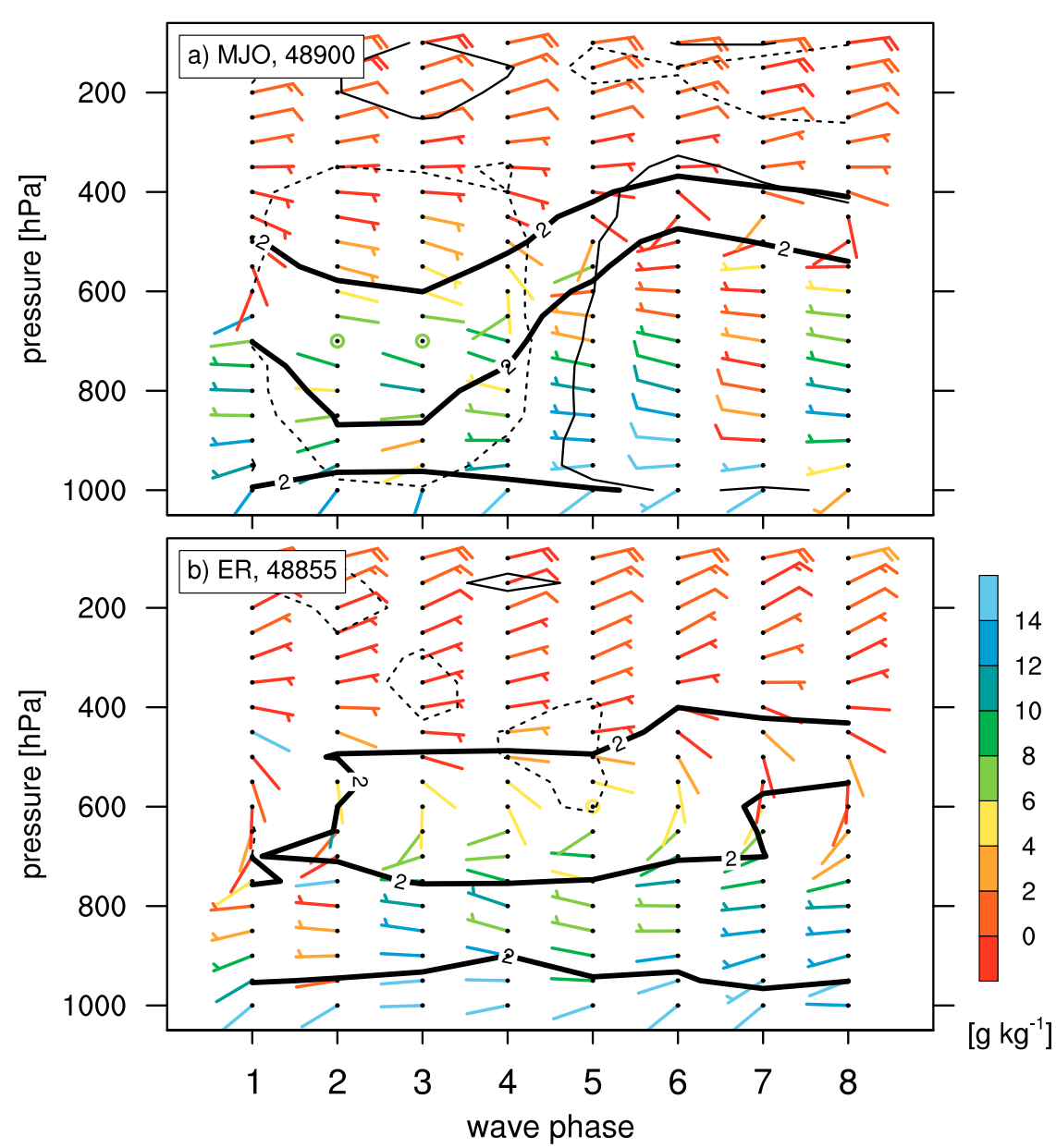

FIG. 7. Vertical profile of vector winds (wind barbs; $\mathrm{m} \mathrm{s}^{-1}$ ), specific humidity (wind barb colors), zonal wind anomalies (dashed and solid; thin contour lines for easterly and westerly wind anomalies equal to $1 \mathrm{~m} \mathrm{~s}^{-1}$, respectively), and $2 \mathrm{~m} \mathrm{~s}^{-1}$ isotach (thick contour lines) per phase of (a) the Madden-Julian oscillation and (b) equatorial Rossby waves during MayOctober. Source: IGRA data for Ho Chi Minh City in (a), and for Da Nang in (b).

preceded by westerly wind anomalies. Note that the atmosphere is exceptionally dry in the $900-100-\mathrm{hPa}$ layer in phase 7 . The pattern of low-level easterly (westerly) and upper-level westerly (easterly) wind anomalies before the wet (dry) phases is similar to the profiles of zonal wind anomalies at Diego Garcia in the central equatorial Indian Ocean, as shown by Kiladis et al. (2005). These results are also consistent with the classical scheme of the MJO circulation, as depicted in Fig. 16 of Madden and Julian (1972).

Dry and wet phases of the MJO also exhibit a discernible influence on the occurrence of intensity intervals of daily station rainfall (Fig. 8). During wet phases of the MJO, the frequency of days with less than $1 \mathrm{~mm}$ rainfall is reduced by about $28 \%$. On the contrary, the number of days with at least $1-\mathrm{mm}$ rainfall is increased during wet phases by about $25 \%$, peaking at an increase of more than $50 \%$ in the number of days with at least 25-mm rainfall. Rainfall anomalies per wave phase averaged over all stations corroborate that phases 8 and 1-3 are dry phases, whereas phases 4-7 are wet phases (Table 1). Moreover, rainfall anomalies in dry and wet phases are significantly enhanced for higher amplitudes of the MJO, except in phases 7 and 8 (Table 1).

\section{b. Kelvin waves}

In the Maritime Continent region, the highest OLR variance in the Kelvin wave band is observed close to the equator (Fig. 3b) and gradually decreases northward toward Vietnam. In the whole latitude belt depicted in Fig. 3b, the highest values occur in the central Pacific and farther northward off the equator. This northward displacement of Kelvin waves follows the location of the ITCZ and is consistent with the findings in previous studies (e.g., Roundy and Frank 2004a; Kiladis et al. 2009). 


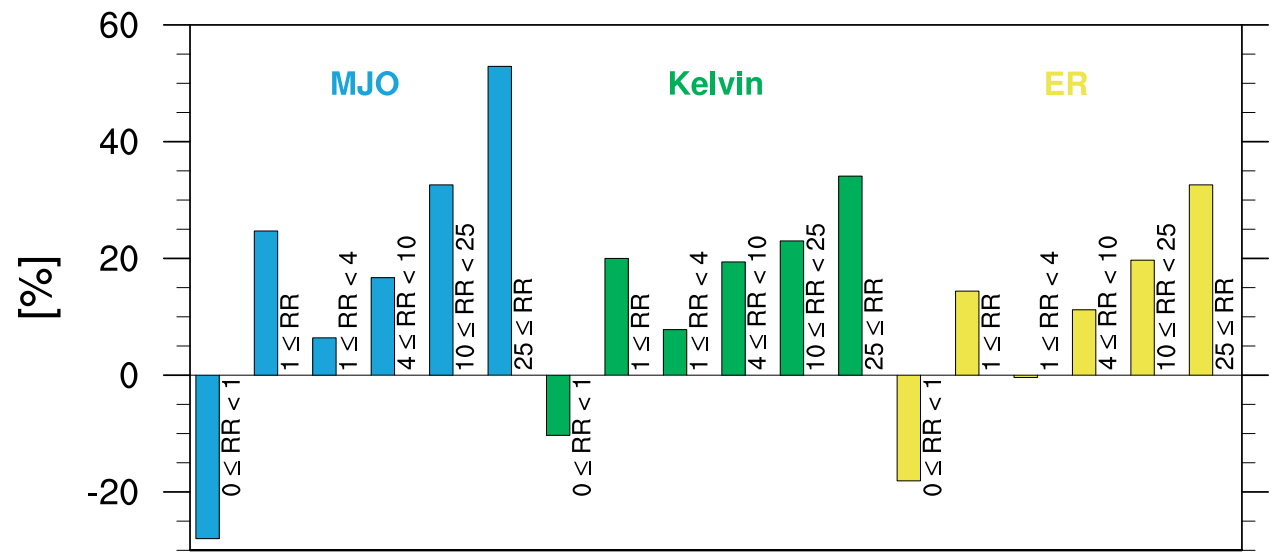

FIG. 8. Influence of wave phases on the frequency of rainfall (RR) intensities $\left(\mathrm{mm} \mathrm{day}^{-1}\right)$. Differences in the number of values in the wet phases 4,5 , and 6 are relative to the number of values in the dry phases 8, 1, and 2 for the Madden-Julian oscillation, Kelvin waves, and equatorial Rossby waves during May-October.

As for the MJO, there is generally a good agreement between APHRODITE and station rainfall anomalies, except for phase 6 of the Kelvin wave, when station anomalies are mostly positive but frequently not significant (Figs. 9f, 10f, 6b, Table S3). In phase 6, significant station anomalies occur south or east of the Annamese Cordillera. However, in general there seems to be no clear influence of the orography on rainfall anomalies for Kelvin waves. In phases 4 and 5, statistically significant positive rainfall anomalies occur mainly southward of $12^{\circ} \mathrm{N}$, peaking at $4 \mathrm{~mm} \mathrm{day}^{-1}$ in phase 5 (Figs. 9e, 10e). Over large parts of southern Vietnam, phase 1 is the driest phase, with deviations of up to $-3 \mathrm{~mm} \mathrm{day}^{-1}$ relative to the long-term mean. Station rainfall is enhanced by about $21 \%-26 \%$ during wet phases and suppressed by about $19 \%-23 \%$ during dry phases in relation to the long-term mean daily rainfall at stations south of $12^{\circ} \mathrm{N}$ (cf. Figs. 10, S1,
Tables S1 and S3). The influence of Kelvin wave activity on $850-\mathrm{hPa}$ winds is not as pronounced as for the MJO, most likely because its influence on the horizontal wind field is more concentrated closer to the equator. This is evident from significant positive (negative) tropospheric moisture flux convergence anomalies in phases 3 and 4 (phases 1, 7, and 8) that again seem to lead rainfall anomalies by about one phase in southern Vietnam and the adjacent SCS (Fig. S3). Nonetheless, statistically significant easterly wind anomalies occur in phases 1 and 4 (Figs. 9a,d). In contrast to the MJO, Kelvin waves do not exhibit such a pronounced modification of the composite vertical profiles of wind and specific humidity in Ho Chi Minh City, except in phases 7 and 8, when a considerable drying of the lower troposphere is observed (Fig. S5). The transitional phases 3 and 7 cannot be considered as entirely dry or wet phases, because

TABLE 1. Influence of wave amplitudes (AMP) on rainfall anomalies during May-October. Anomalies $\left(\mathrm{mm} \mathrm{day}^{-1}\right)$ are shown, and numbers in brackets indicate the number of days in the wave phase and amplitude interval. Bold numbers indicate statistically significant values. Rainfall anomalies for amplitudes greater than 2 are marked with an asterisk, if the anomalies are significantly different from anomalies for $1<$ AMP $\leq 2$. Results are shown for the Madden-Julian oscillation, Kelvin waves, and equatorial Rossby waves.

\begin{tabular}{|c|c|c|c|c|c|c|c|c|c|}
\hline & & \multicolumn{8}{|c|}{ Wave phase } \\
\hline & & 1 & 2 & 3 & 4 & 5 & 6 & 7 & 8 \\
\hline \multirow[t]{3}{*}{ MJO } & $\mathrm{AMP}>1$ & $\mathbf{- 1 . 8}(700)$ & -2.2 (664) & -1.0 (660) & $1.1(649)$ & $2.8(643)$ & $2.4(624)$ & $0.6(650)$ & $-1.0(656)$ \\
\hline & $1<\mathrm{AMP} \leq 2$ & -0.8 (371) & $\mathbf{- 1 . 4}(317)$ & $-\mathbf{0 . 7}(286)$ & $0.6(252)$ & $1.9(282)$ & $1.2(263)$ & $0.7(260)$ & $\mathbf{- 1 . 3}(287)$ \\
\hline & $\mathrm{AMP}>2$ & $\mathbf{- 2 . 8 *}(329)$ & $\mathbf{- 2 . 8 *}(347)$ & $\mathbf{- 1 . 2} *(374)$ & $1.4 *(397)$ & 3.4* (361) & $3.2 *(361)$ & $0.5(390)$ & -0.8 (369) \\
\hline \multirow[t]{3}{*}{ Kelvin } & $\mathrm{AMP}>1$ & $\mathbf{- 1 . 0}(451)$ & $\mathbf{- 0 . 7}(411)$ & $-0.1(334)$ & $0.7(423)$ & $1.2(463)$ & $1.0(395)$ & $-0.1(383)$ & $\mathbf{- 0 . 6}(377)$ \\
\hline & $1<\mathrm{AMP} \leq 2$ & $-\mathbf{1 . 2}(388)$ & $-0.8(349)$ & $-0.1(286)$ & $0.8(363)$ & $1.1(380)$ & $1.0(333)$ & $0.1(324)$ & $-0.4(318)$ \\
\hline & $\mathrm{AMP}>2$ & $-0.1(63)$ & $-0.4(62)$ & $0.2(48)$ & $0.2(60)$ & $1.5(83)$ & $1.1(62)$ & $-0.8^{*}(59)$ & $-\mathbf{1 . 5}^{*}(59)$ \\
\hline \multirow[t]{3}{*}{ ER } & $\mathrm{AMP}>1$ & -1.4 (612) & $\mathbf{- 0 . 7}(571)$ & $0.2(588)$ & $1.5(548)$ & $1.9(573)$ & 0.9 (582) & $-0.0(566)$ & $\mathbf{- 0 . 7}(584)$ \\
\hline & $1<\mathrm{AMP} \leq 2$ & -1.5 (362) & $-0.8(313)$ & $\mathbf{- 0 . 7}(327)$ & $0.9(303)$ & $0.5(319)$ & $0.3(327)$ & $-0.4(313)$ & $-\mathbf{0 . 8}(340)$ \\
\hline & $\mathrm{AMP}>2$ & $-1.2(250)$ & $-0.4(258)$ & $\mathbf{1 . 3}^{*}(261)$ & $2.2 *(245)$ & $3.7 *(254)$ & $1.7 *(255)$ & $0.4 *(253)$ & $-0.5(244)$ \\
\hline
\end{tabular}



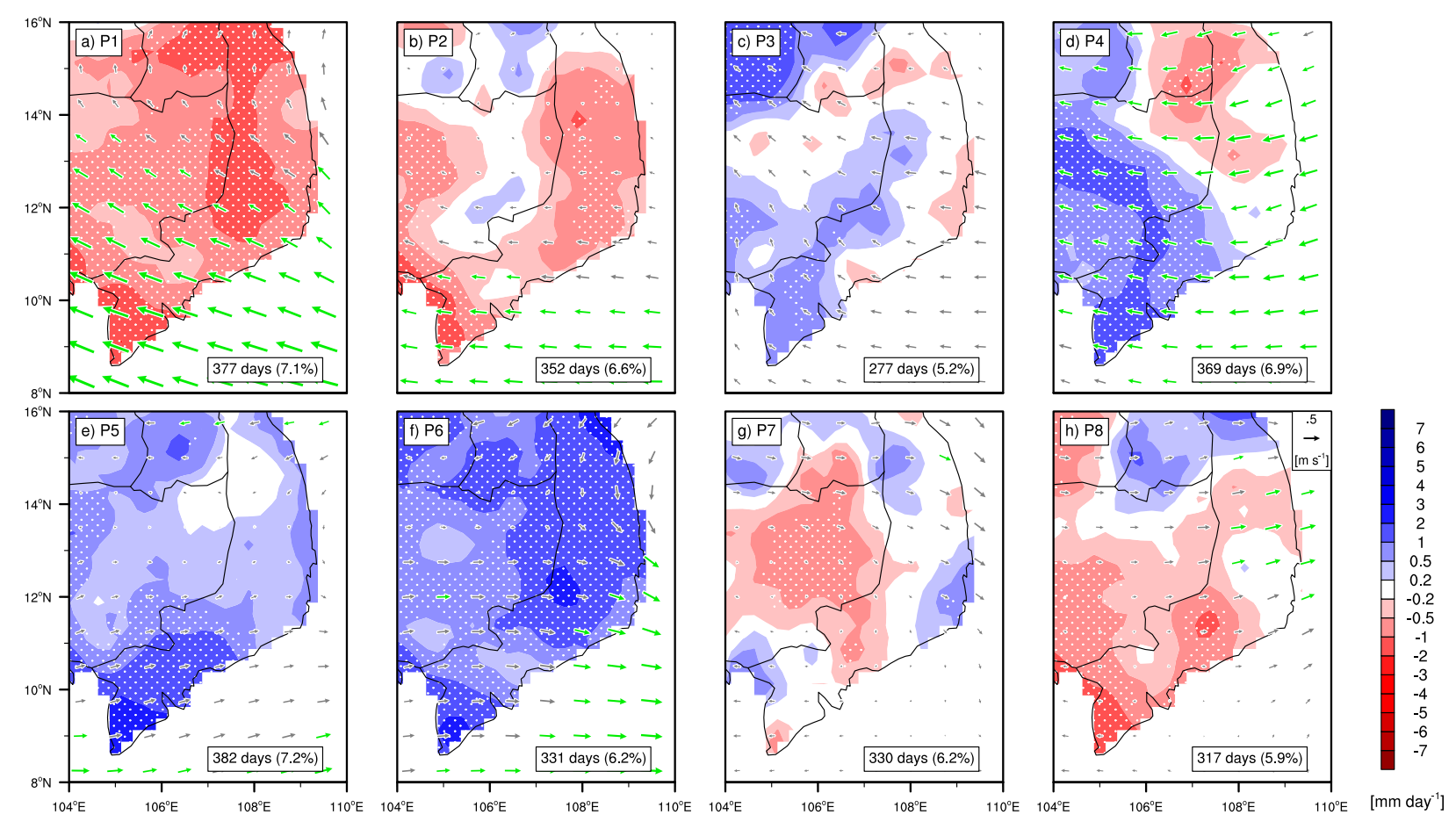

FIG. 9. As in Fig. 4, but for Kelvin waves.

anomalies are incoherently positive or negative, and only few anomalies are significant (Figs. 9c,g, 10c,g, $6 b)$. The dependency between wave phase and daily rainfall intensity is also less pronounced for Kelvin waves than for the MJO (Fig. 8). However, the frequency of days with less than 1-mm rainfall is reduced by $10 \%$ and for days with at least $1 \mathrm{~mm}$ during wet phases frequency increased by about $20 \%$ when compared with the number of days in the respective intervals during dry phases. Area-averaged station rainfall anomalies do not show a pronounced relationship between amplitude and anomaly (Table 1).

\section{c. Equatorial Rossby waves}

In accordance with the theoretical horizontal structures of ER waves (e.g., Kiladis et al. 2009), local variance maxima of ER wave-filtered OLR occur northward and southward of the equator (Fig. 3c). During the rainy season, the OLR variance in the southern half of Vietnam is about $50 \%-75 \%$ of the maximum variance that peaks north of the Philippine Luzon Island. The variance maximum in the Southern Hemisphere is weaker than that in the Northern Hemisphere.

During phases 5 and 6, positive rainfall anomalies are higher on the western side of the Annamese Cordillera (Figs. 11e,f, 12e,f) because of an enhancement of convection in this region. Overall, phases 4 and 5 are the wettest phases, with significant rainfall anomalies of up to about $5 \mathrm{~mm} \mathrm{day}^{-1}$ (Figs. 6c, 11d,e, 12d,e). In agreement with the highest OLR variance in the north of the region, rainfall anomalies are highest in the north and decrease southward. This behavior is most pronounced during phase 5. Compared with Kelvin wave anomalies, ER waves show a larger-scale and more coherent influence (cf. Figs. 9, 10 with Figs. 11, 12). In the north of the region (north of $12^{\circ} \mathrm{N}$ ), where rainfall anomalies are highest, station rainfall is enhanced by about $24 \%-36 \%$ during wet phases and suppressed by about $17 \%-27 \%$ during dry phases in relation to the longterm mean (cf. Figs. 12, S1, Tables S1 and S4). On the contrary, when averaged over stations south of $12^{\circ} \mathrm{N}$, rainfall is enhanced only by about $21 \%-24 \%$ during wet phases and reduced by about $17 \%-19 \%$ during dry phases. The transitional phases 3 and 7 do not show a predominant or significant deviation from the long-term mean (Fig. 6c, Table S4). Westerly winds are significantly enhanced during phases 4 and 5, and anomalies are easterly during phases 8 and 1; during the other phases, the wind is not influenced substantially (Figs. 11, 12). Again, moisture flux convergence seems to precede rainfall anomalies by one phase (Fig. S4). As for the MJO, westerly wind anomalies seem to enhance orographic rainfall on the westward side of the Annamese Cordillera. Because of 

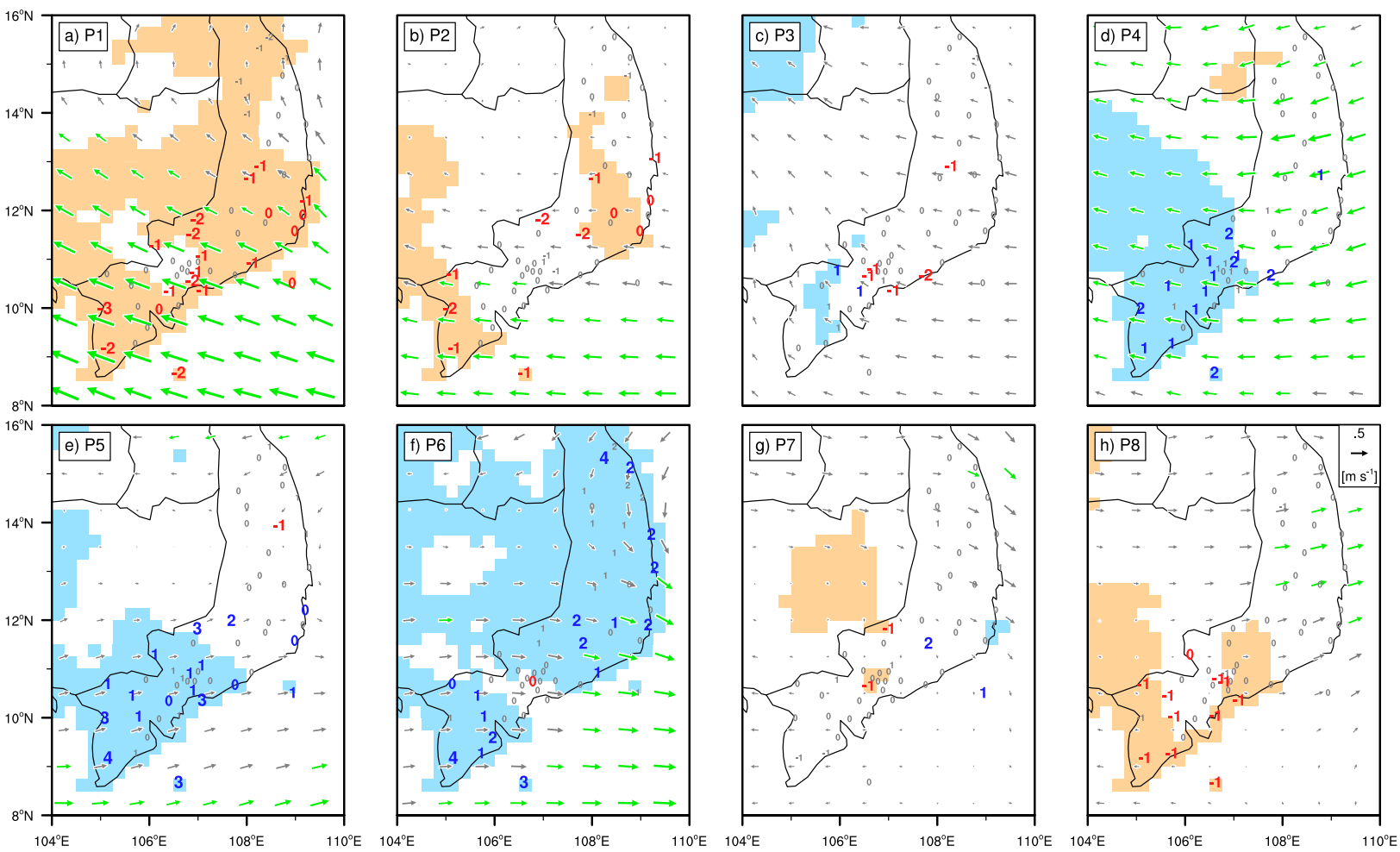

FIG. 10. As in Fig. 5, but for Kelvin waves.

the strongest influence of ER waves in the north of the area, ER wave influence is more easily discernible in radiosonde data from Da Nang than from Ho Chi Minh City (cf. Figs. 7b, S6). In contrast to the MJO, which modulates the vertical wind and humidity profiles, the influence of ER waves is more pronounced for composite humidity profiles: the depth of high, lower-level humidity is clearly increased during wet phases of ER waves (Fig. 7b). The relation between wave phase and rainfall intensity is even weaker than for Kelvin waves, but the influence of wave amplitudes on area-averaged station rainfall anomalies is more pronounced when compared with Kelvin wave composites (Fig. 8 and Table 1), possibly because of the more coherent rainfall anomalies for ER wave phases (cf. Figs. 10, 12). Primarily for the wet phases, rainfall anomalies are higher for higher-amplitude ER waves (Table 1).

\section{d. Combined effects of multiple large-scale equatorial waves}

In this section, the modulating influence of the concurrent occurrence of different waves is determined. Previously, Roundy (2008) and Roundy and Frank $(2004 b, c)$ found interactions between the MJO and Kelvin waves and between the MJO and ER waves, respectively. Here, we test the idea that the concurrence of the MJO and CCEWs can be represented by linear superposition of the signals of each, although we do not necessarily expect that to be the case, as for the example of Kelvin waves within the MJO (e.g., Roundy 2008).

The influence of the concurrent occurrence of different MJO phases during certain Kelvin and ER wave phases on daily station rainfall is evaluated here, introducing a new type of wave interference diagram that is schematically illustrated in Fig. 13. The diagram consists of two levels of phase diagrams: one outer phase diagram for wave $1\left(\mathrm{~W} 1\right.$; Fig. $\left.13 \mathrm{a} ; \mathrm{P} 1_{\mathrm{W} 1}-\mathrm{P} 8_{\mathrm{W} 1}\right)$ that refers to the phases of Kelvin or ER waves in this study and, for each phase of $\mathrm{W} 1$, one inset phase diagram for wave 2 (W2). The inset phase diagram exhibits rainfall modulation during the simultaneous occurrence of all eight MJO phases $\left(\mathrm{P}_{\mathrm{W}_{2}}-\mathrm{P} 8_{\mathrm{W} 2}\right)$ during the fixed given phase of W1. Note that any other combination of MJO and CCEWs can be used for W1 and W2. Figure 13b is an example for such an inset phase diagram for phase 1 of W1. The coloring of the phase segments of the outer and inset phase diagrams in Figs. 13a and 13b suggests the expected dry (reddish colors, right segments) and wet (bluish colors, left segments) anomalies during these phases. Yellow-colored segments indicate the transitional phases. The outer and inset phase diagrams start with phase 1 in the middle-right position and proceed clockwise from phase 2 to 8 , as indicated by the circle in Figs. 13a and 13b. The three major components of this 

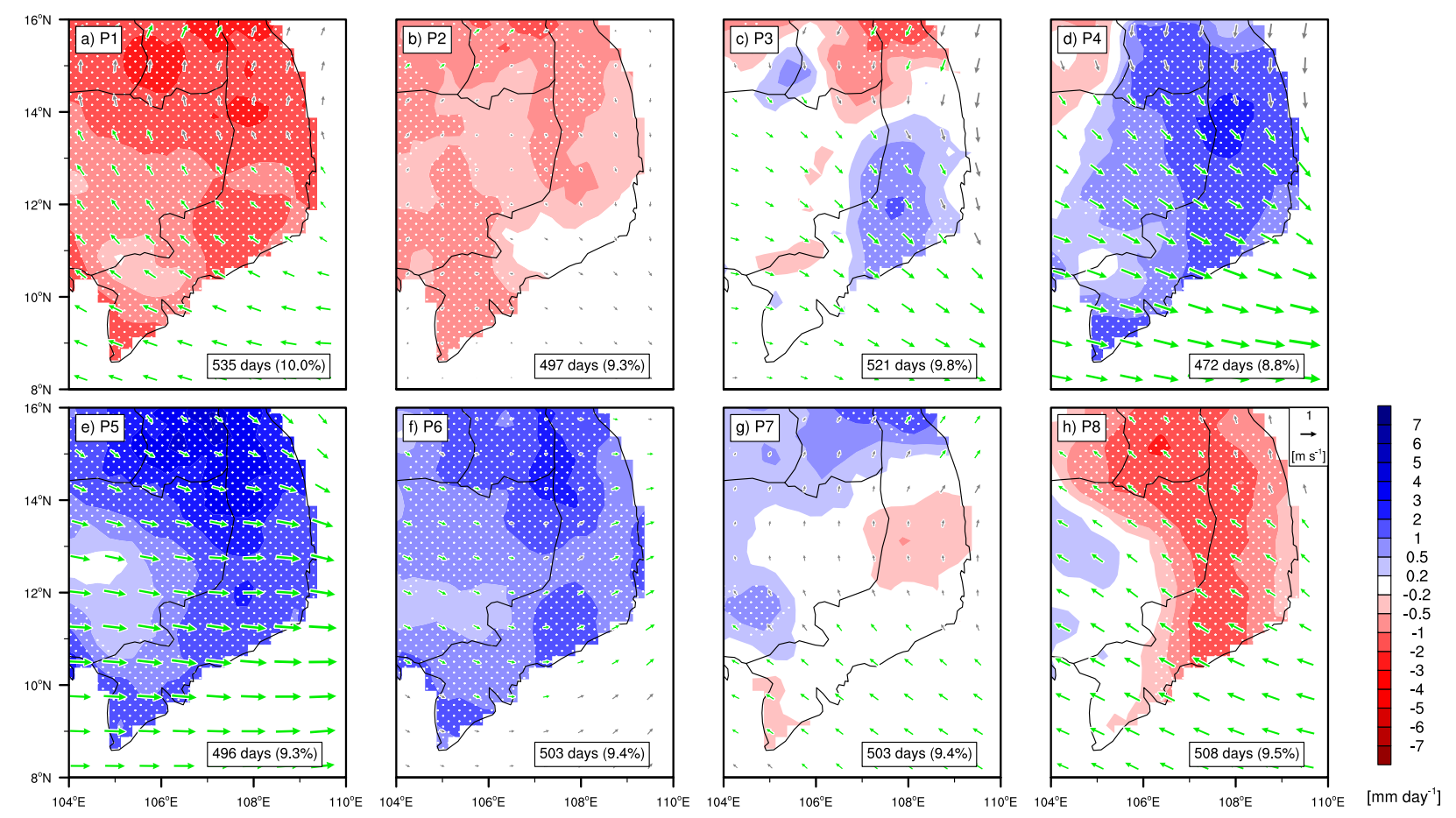

FIG. 11. As in Fig. 4, but for equatorial Rossby waves.

new diagram, denoted as A, B, and C in Fig. 13b, provide more detailed information. Component $\mathrm{A}$ includes information about the name of wave 1 , about the wave's current phase $\left(\mathrm{P}_{\mathrm{W} 1}\right)$, and about the area-averaged rainfall anomaly for phase $\mathrm{P}_{\mathrm{W} 1}$. The color of the segment in component $\mathrm{B}$ indicates the rainfall anomaly of concurrent phases $\mathrm{P}_{\mathrm{W} 1}$ and $\mathrm{P}_{\mathrm{W} 2}$. The first number in the inset white box indicates how the anomaly of $\mathrm{P}_{\mathrm{W} 1}$ is modulated, if $\mathrm{P}_{\mathrm{W} 1}$ and $\mathrm{P}_{\mathrm{W} 2}$ occur concurrently, and the percentage indicates the frequency of this concurrent occurrence. Since only waves with amplitudes greater than one are considered (cf. section 2), component $\mathrm{C}$ indicates the percentage of days during phase $\mathrm{P}_{\mathrm{W} 1}$ when the amplitude of W2 is lower than or equals one. In this example, component $\mathrm{B}$ depicts the segment for $\mathrm{P} 1_{\mathrm{W} 2}$ during $\mathrm{P} 1_{\mathrm{W} 1}$.

Figure 14 shows the phase interference diagram for Kelvin waves and the MJO. Overall, MJO phases 5 and 6 that are in the top-left corner of the inset W2 phase diagram show the largest influence in all Kelvin wave phases (Fig. 14). Even in the dry Kelvin wave phases 8,1, and 2 (right panels of the outer W1 phase diagram), the concurrent occurrence of the wet MJO phases 5 and 6 results in significant wet rainfall anomalies (i.e., the MJO overrides the dry signal of the Kelvin waves when it is in its wet phases). The aforementioned anomalies are also significantly different from rainfall anomalies in these Kelvin wave phases when no specific MJO phase is required. The strongest influence of the MJO is observed during the transitional Kelvin wave phase 3 when the MJO is concurrently in phase 5: the area-averaged rainfall anomaly is increased by $5.6 \mathrm{~mm} \mathrm{day}^{-1}$ in this combination of wave phases. Rainfall anomalies during dry Kelvin waves are also amplified by concurrent dry MJO phases. Dry MJO phases also show an influence during the wet Kelvin wave phases 4, 5, and 6. However, rainfall anomalies are mostly not modified significantly on these days. The strongest drying influence of the MJO with about $-2.6 \mathrm{~mm}$ day $^{-1}$ occurs for the combination of Kelvin wave phases 1 and 2 with MJO phases 2 and 1 , respectively.

Results for the combination of ER wave phases and MJO phases (Fig. 15) show similar results as for the combination of Kelvin waves and the MJO (Fig. 14). Wet MJO phases also have a significant influence on all ER wave phases, as can be seen by the blue, stippled segment on the left side of all outer W1 phase diagram positions. However, the amplification of positive rainfall anomalies is more pronounced, and the percentage of wet MJO phases during wet ER wave phases is generally higher: namely, $9.9 \%-13.6 \%$ for ER waves versus $10.2 \%-10.8 \%$ for Kelvin waves in phase 5 . Additionally, the frequency of occurrence of ER waves is for all phases higher than for Kelvin waves $(8.8 \%-10 \%$ vs $5.2 \%-7.2 \%$; cf. Figs. 9 and 11). The strongest modulation of rainfall anomalies occurs for the concurrent 

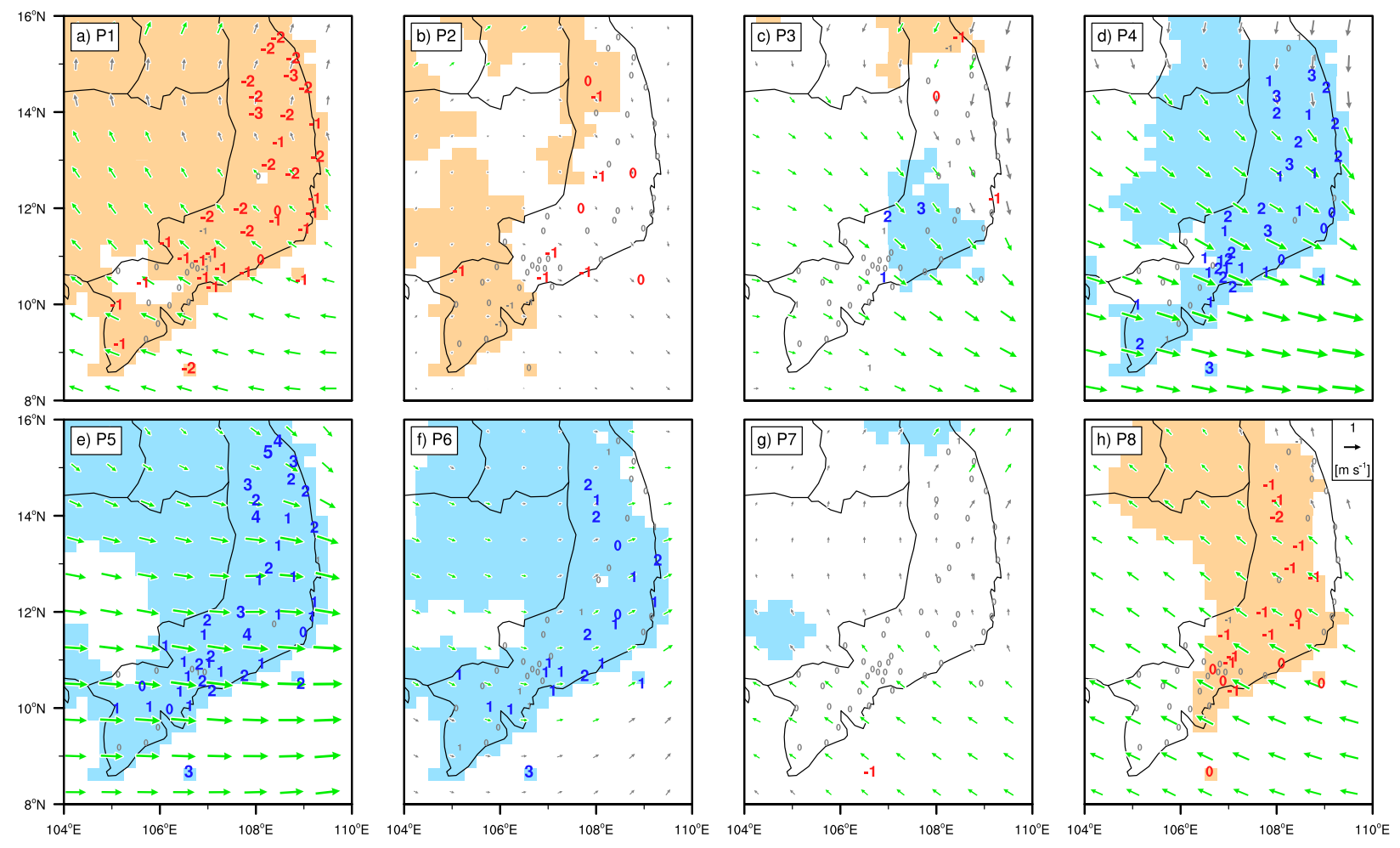

FIG. 12. As in Fig. 5, but for equatorial Rossby waves.

occurrence of ER wave phase 5 and MJO phase 4 $\left(+4.1 \mathrm{~mm} \mathrm{day}^{-1}\right)$, when area-averaged rainfall anomalies also reach their maximum with more than $6 \mathrm{~mm}_{\text {day }}{ }^{-1}$. A possible explanation is that ER waves affect a larger area of southern Vietnam compared to Kelvin waves (cf. Figs. 9 and 11). Moreover, the propagation speeds of ER waves are slower than for Kelvin waves, which might play an additional role. Overall, the influence of the MJO seems to be slightly stronger on ER waves than on Kelvin waves. The wave interference diagrams shown in Figs. 14 and 15 have been replotted in the supplemental material by simply adding or subtracting the MJO anomalies to each of the phases of Kelvin and ER waves (Figs. S7 and S8). In this "linear response" case, the MJO modulates rainfall anomalies almost irrespectively of the specific phases of Kelvin and ER waves because of the dominance of the MJO response amplitudes. In reality, the MJO is made up in part of CCEWs, so it likely modulates, and is modulated by, its nonlinear interaction with those modes.

\section{Summary and discussion}

The modulating influence of the MJO and CCEWs on daily rainfall during the rainy season from May to October in southern Vietnam was investigated using an extensive station database and the gridded APHRODITE product. Based on filtered variance of OLR in the wavenumber-frequency domains of several large-scale equatorial waves, the MJO and convectively coupled Kelvin and ER waves were selected for an in-depth investigation. For all waves, different phases from dry to wet were determined regionally using normalized, wave-filtered OLR and the normalized temporal change of wave-filtered values.

The MJO exhibits the largest influence on daily rainfall both in terms of magnitude and spatial extension. Statistically significant deviations from the mean were found for large regions in southern Vietnam during all MJO phases. ER waves also affect the whole region, with stronger amplitudes in the northern part. On the contrary, for Kelvin waves, the largest modulation of rainfall is confined to regions south of $12^{\circ} \mathrm{N}$. Overall, the long-term mean daily station rainfall is enhanced by about $20 \%-36 \%$ during wet phases of the equatorial waves and suppressed by about $17 \%-27 \%$ during dry phases. For all waves, no indication of an asymmetric response of rainfall to dry and wet phases could be detected. An asymmetric response only arises when considering the amplitudes of the waves, as ER waves show a stronger anomaly of area-averaged rainfall for the wet phases for higher amplitudes. For the MJO, the amplitude-related response remains symmetric, whereas any amplitude impact is weak for Kelvin waves, 


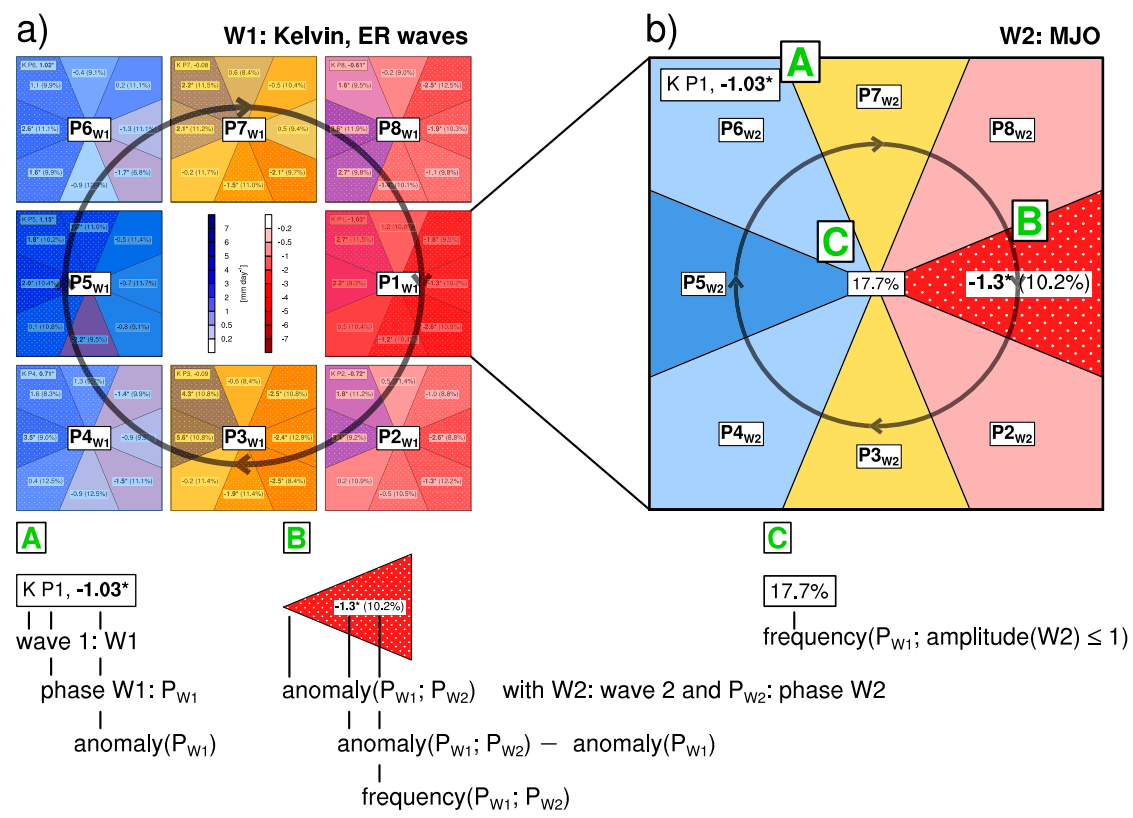

FIG. 13. Schematic illustration of the composition of Figs. 14 and 15. (a) Outer-phase diagram for wave 1 that refers to the eight phases $\mathrm{P} 1_{\mathrm{W} 1}$ to $\mathrm{P} 8_{\mathrm{W} 1}$ of Kelvin and ER waves in Figs. 14 and 15, respectively (b) Inset phase diagram for wave 2 (the MJO in the present study) during the fixed given phase of $\mathrm{W} 1$ (here $\mathrm{P} 1_{\mathrm{W} 1}$ ). Stippled areas and boldfaced numbers with asterisks indicate statistically significant values. The three major components $\mathrm{A}, \mathrm{B}$, and $\mathrm{C}$ in (b) are explained in the legends below the panels and in section 3d. Phase progression is clockwise, as indicated by the circles, with phase 1 being in the middle-right position of the rectangle.

possibly because their influence is limited to the southernmost part of Vietnam. The frequency of rainfall intensities depends on the phases of all equatorial waves considered here. The frequency of days without substantial rainfall is reduced, and that of days with higherintensity rainfall is increased during wet phases when compared with the number of days during the respective intensity intervals during dry phases. Again, the strongest signal relates to the wet phases of the MJO; that is, the probability of extreme rainfall that is potentially leading to flooding is increased all over southern Vietnam. A similar result has been documented previously by Wheeler and Hendon (2004) for Australia.

For the MJO, 850-hPa winds are anomalously westerly during most wet phases and anomalously easterly during most dry phases of the MJO. These anomalies are relative to the basic westerly flow. Thus, stronger westerlies associated with the MJO, and albeit weaker, with ER waves seem to further enhance orographic rainfall on the windward (westward) side of the Annamese Cordillera, whereas easterly anomalies do not show orographically enhanced rainfall at its eastern side. Based on radiosondes from Ho Chi Minh City, it was found that the MJO also enhances the depth of the moist westerly monsoon flow and increases deep vertical wind shear during wet phases, leading to favorable conditions for the organization of convection. In radiosondes from Da Nang, ER wave influence was rather constrained to follow lower-tropospheric humidity, showing a deeper moist layer during wet phases when compared with dry phases. Changes in wind and humidity profiles for Kelvin waves were less clear, likely as a result of this signal being more confined to equatorial latitudes.

The strong, symmetric, and amplitude-related impact of rainfall in the MJO case opens new avenues for medium-range weather forecasting for the Indochina Peninsula. Zhang and van den Dool (2012) and Saha et al. (2014) have shown that skillful forecasts of the MJO in the Climate Forecast System (CFS), version 2, were improved from 6 to 17 days relative to version 1 of CFS. Recently, Goswami et al. (2015) have shown an improved representation of CCEWs in superparameterized CFS, version 2, runs. Since Straub et al. (2006) and Tong et al. (2009) demonstrated that the MJO influences the monsoon onset, this also bears on the potential of two-week forecasts of the SCS summer monsoon onset. Forecasting guidance may be aided by the fact that tropospheric moisture convergence (divergence) leads positive (negative) rainfall anomalies by one phase that can last up to one week for MJO. 

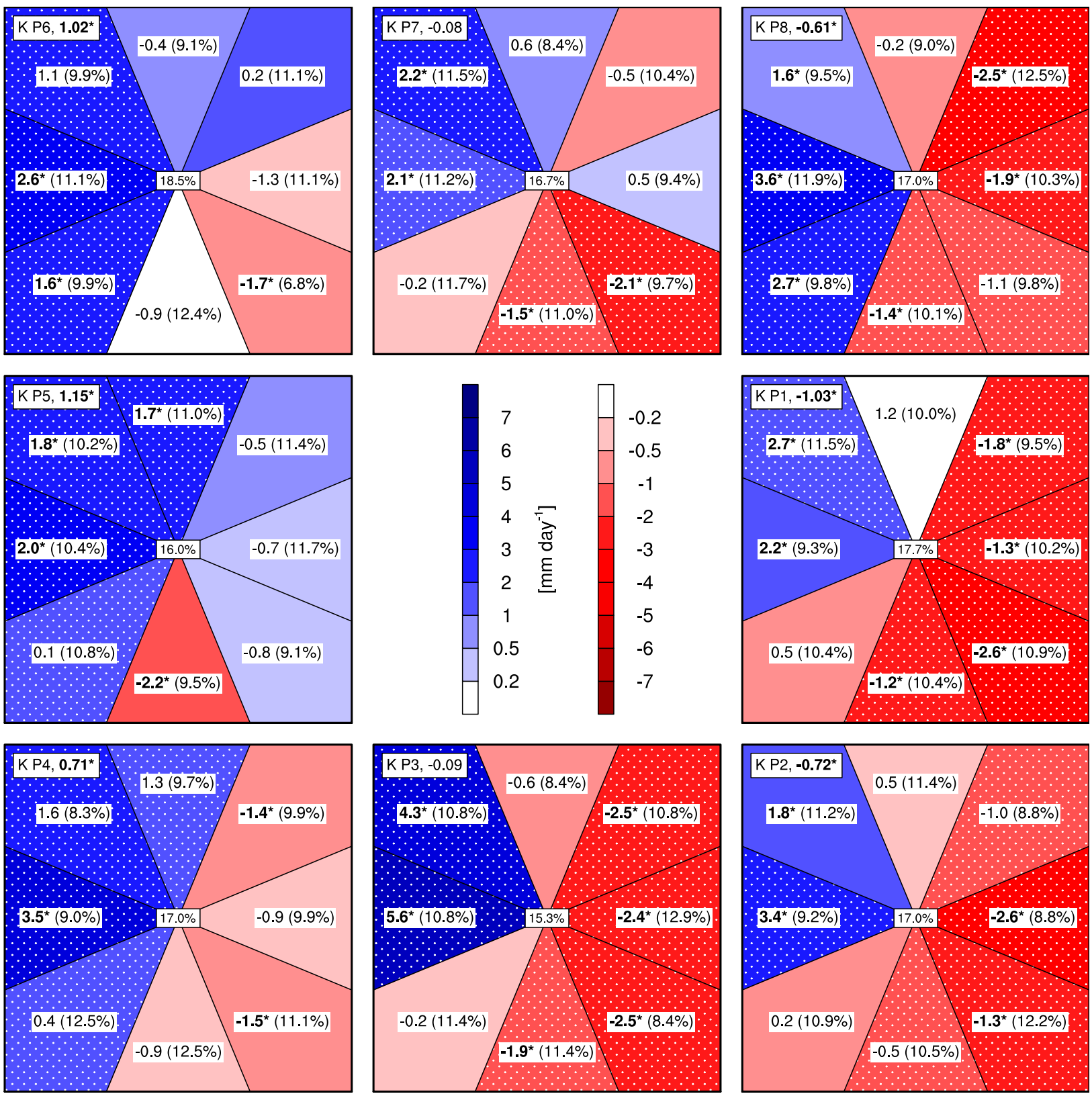

FIG. 14. Rainfall anomalies ( $\mathrm{mm} \mathrm{day}^{-1}$ ) (see inset label bars) during concurrent occurrences of different combinations of Kelvin wave and Madden-Julian oscillation phases during May-October. Stippled areas and boldfaced numbers with asterisks indicate statistically significant values. See Fig. 13 and section $3 \mathrm{~d}$ for details.

Moreover, errors of medium-range ensemble precipitation forecasts may depend on the MJO amplitude and phase that may allow for a regime-dependent postprocessing of ensemble forecasts. Additionally, these regimes could be used for the evaluation of episodes of potential drought or flooding. With a concomitant further improvement of medium-range CCEW forecasting, drought or flood forecasting for southern Vietnam between May and October might even improve further: this study found that the enhancement and suppression of convection is significantly amplified if the MJO wet/dry phases occur simultaneously with the corresponding phases of Kelvin or ER waves. In this context, the finding of the impact of the ER (Kelvin) waves, being more coherent in central (southern) Vietnam, is relevant.

The present study yields new insights regarding the use of a rain gauge-based gridded rainfall product versus using a relatively dense, but irregularly distributed rain gauge network. In general, a rather good agreement 

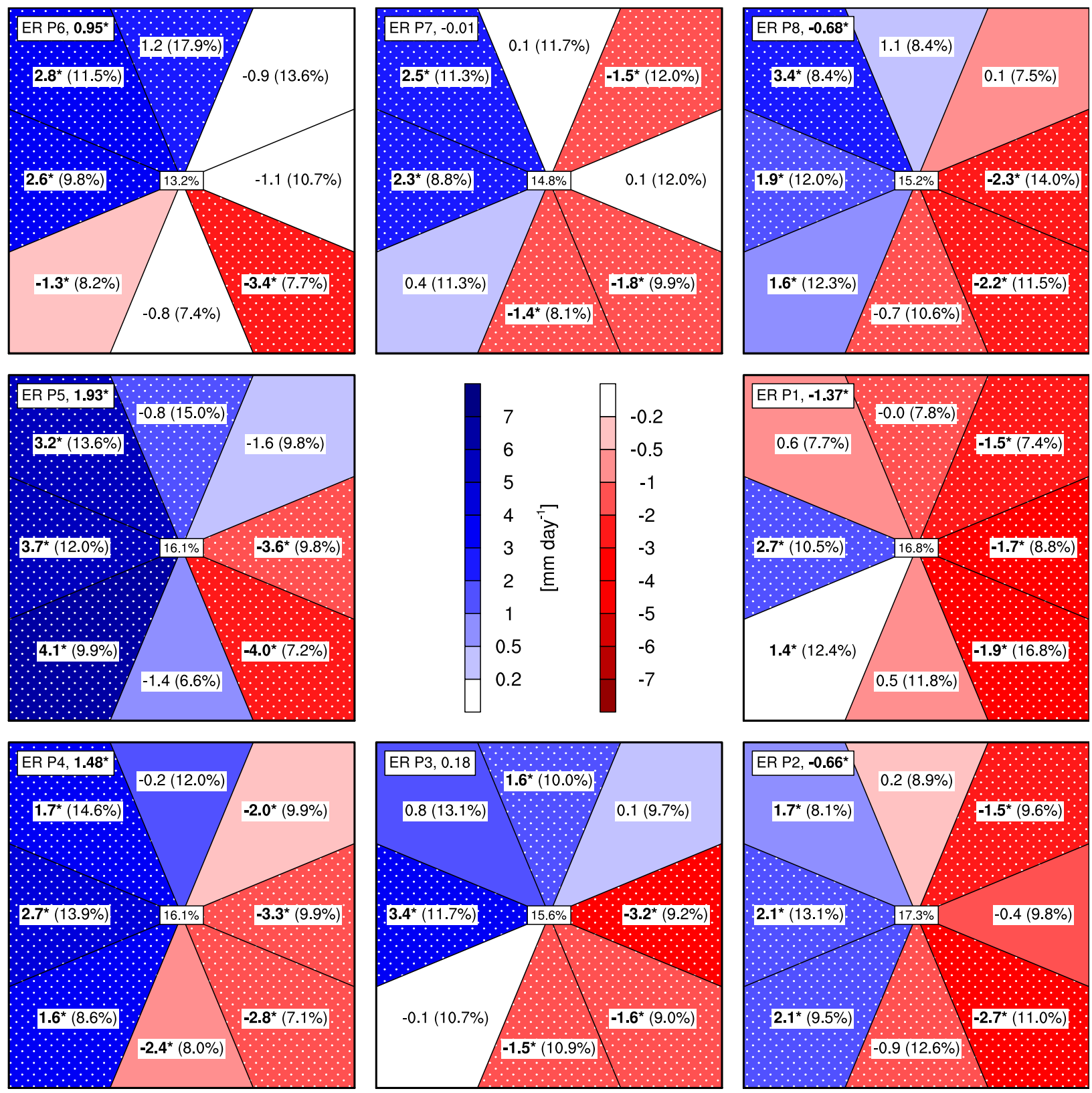

FIG. 15. As in Fig. 14, but for W1 being the equatorial Rossby wave instead of the Kelvin wave.

was found between station and APHRODITE anomalies for waves with a coherent influence on rainfall in southern Vietnam, namely, for the MJO and for ER waves. However, in phases for which the significant rainfall anomalies start to weaken or strengthen, APHRODITE tends to smear out significant areas over regions where several stations do not pass the significance test. This pertains to the Kelvin waves in all phases except 1 (driest) and 5 (wettest), which influence a smaller area mainly in the southern part of the study region. There are two potential causes for differences between
APHRODITE and the station database: on the one hand, NHMS stations used in this study might not have been included in the production of the APHRODITE dataset; on the other hand, regional differences between neighboring stations that fall into one APHRODITE $0.25^{\circ}$ grid might have been smoothed by APHRODITE production algorithms (cf. supplemental material). Thus, for local predictions, the use of raw rain gauge data in assessing the wave influence and to postprocess ensemble rainfall predictions seems to be a better choice over the gridded product. This also pertains to 
applications in agronomy and hydrology, where the use of absolute rainfall thresholds is common.

In terms of weather prediction, the present study leaves open the question as to what types of moist convection lead to positive rainfall anomalies during the wet phases of the waves. All waves cause a moistening of the troposphere, but only the MJO changes the depth of the monsoon layer and the vertical profile of winds. Thus, only the latter suggests improved environmental conditions for self-organization of convection into MCSs. Another possibility is that disturbances in the monsoon flow are more frequently accompanied by convection because of the very unstable and moist lower troposphere during the wet phases. Investigating the modulation of types of convection would be an obvious next step.

In terms of climate projections, the latest IPCC Assessment Report states that future changes in $\mathrm{MJO}$ activity are uncertain (Christensen et al. 2013). However, Schubert et al. (2013) documented an increase of MJO variance as a response to a warming climate. According to our study, this would suggest a stronger modulation of monsoon rainfall over the Indochina Peninsula. But even in case of unchanged variance, a future moister atmosphere could enhance wave-related rainfall, including extreme rainfall events. Representation of the MJO and CCEWs in global models has improved recently, opening a new avenue for research on regional climate projection in tropical regions.

Acknowledgments. The first three authors acknowledge support for their research leading to these results by the EWATEC-COAST project (BMBF Grant 02WCL1217C). The fourth author acknowledges support for his research from the NAFOSTED project No. 105.06-2014.44. We wish to thank three anonymous reviewers for their valuable comments that helped to substantially improve the manuscript.

\section{REFERENCES}

Anber, U., S. Wang, and A. Sobel, 2014: Response of atmospheric convection to vertical wind shear: Cloud-system-resolving simulations with parameterized large-scale circulation. Part I: Specified radiative cooling. J. Atmos. Sci., 71, 2976-2993, doi:10.1175/JAS-D-13-0320.1.

Arkin, P. A., and P. E. Ardanuy, 1989: Estimating climatic-scale precipitation from space: A review. J. Climate, 2, 1229-1238, doi:10.1175/1520-0442(1989)002<1229:ECSPFS>2.0.CO;2.

Asian Development Bank, 2010: Ho Chi Minh City adaptation to climate change. Asian Development Bank Summary Rep., 43 pp. [Available online at http://www.adb.org/publications/ ho-chi-minh-city-adaptation-climate-change-summary-report.]

Christensen, J. H., and Coauthors, 2013: Climate phenomena and their relevance for future regional climate change. Climate
Change 2013: The Physical Science Basis, T. F. Stocker, et al., Eds., Cambridge University Press, 1217-1308, doi:10.1017/ CBO9781107415324.028.

Dee, D. P., and Coauthors, 2011: The ERA-Interim reanalysis: Configuration and performance of the data assimilation system. Quart. J. Roy. Meteor. Soc., 137, 553-597, doi:10.1002/ qj. 828.

Dias, J., and G. N. Kiladis, 2014: Influence of the basic state zonal flow on convectively coupled equatorial waves. Geophys. Res. Lett., 41, 6904-6913, doi:10.1002/2014GL061476.

_ and _ 2016: The relationship between equatorial mixed Rossby-gravity and eastward inertio-gravity waves. Part II. J. Atmos. Sci., 73, 2147-2163, doi:10.1175/JAS-D-15-0231.1.

Durre, I., R. S. Vose, and D. B. Wuertz, 2006: Overview of the Integrated Global Radiosonde Archive. J. Climate, 19, 53-68, doi:10.1175/JCLI3594.1.

General Statistics Office of Vietnam, 2016: Exports of goods in 2014. General Statistics Office of Vietnam, accessed 10 March 2016. [Available online at http://www.gso.gov.vn/Modules/ Doc_Download.aspx?DocID $=17481$.]

Goswami, B. B., R. P. M. Krishna, P. Mukhopadhyay, M. Khairoutdinov, and B. N. Goswami, 2015: Simulation of the Indian summer monsoon in the superparameterized Climate Forecast System version 2: Preliminary results. J. Climate, 28, 8988-9012, doi:10.1175/JCLI-D-14-00607.1.

Houze, R. A., K. L. Rasmussen, M. D. Zuluaga, and S. R. Brodzik, 2015: The variable nature of convection in the tropics and subtropics: A legacy of 16 years of the Tropical Rainfall Measuring Mission satellite. Rev. Geophys., 53, 994-1021, doi:10.1002/2015RG000488.

Kiladis, G. N., K. H. Straub, and P. T. Haertel, 2005: Zonal and vertical structure of the Madden-Julian oscillation. J. Atmos. Sci., 62, 2790-2809, doi:10.1175/JAS3520.1.

- M. C. Wheeler, P. T. Haertel, K. H. Straub, and P. E. Roundy, 2009: Convectively coupled equatorial waves. Rev. Geophys., 47, RG2003, doi:10.1029/2008RG000266.

_ J. Dias, K. H. Straub, M. C. Wheeler, S. N. Tulich, K. Kikuchi, K. M. Weickmann, and M. J. Ventrice, 2014: A comparison of OLR and circulation-based indices for tracking the MJO. Mon. Wea. Rev., 142, 1697-1715, doi:10.1175/ MWR-D-13-00301.1.

, _ _ a and M. Gehne, 2016: The relationship between equatorial mixed Rossby-gravity and eastward inertio-gravity waves. Part I. J. Atmos. Sci., 73, 2123-2145, doi:10.1175/ JAS-D-15-0230.1.

Liebmann, B., and C. A. Smith, 1996: Description of a complete (interpolated) outgoing longwave radiation dataset. Bull. Amer. Meteor. Soc., 77, 1275-1277.

Lubis, S. W., and C. Jacobi, 2015: The modulating influence of convectively coupled equatorial waves (CCEWs) on the variability of tropical precipitation. Int. J. Climatol., 35, 14651483, doi:10.1002/joc.4069.

Madden, R. A., and P. R. Julian, 1971: Detection of a 40-50 day oscillation in the zonal wind in the tropical Pacific. J. Atmos. Sci., 28, 702-708, doi:10.1175/1520-0469(1971)028<0702: DOADOI $>2.0 . \mathrm{CO} ; 2$.

, and - 1972: Description of global-scale circulation cells in the tropics with a 40-50 day period. J. Atmos. Sci., 29, 1109-1123, doi:10.1175/1520-0469(1972)029<1109:DOGSCC > 2.0.CO;2.

Masunaga, H., 2007: Seasonality and regionality of the MaddenJulian oscillation, Kelvin wave, and equatorial Rossby wave. J. Atmos. Sci., 64, 4400-4416, doi:10.1175/2007JAS2179.1. 
- 2009: A 9-season TRMM observation of the austral summer MJO and low-frequency equatorial waves. J. Meteor. Soc. Japan, 87A, 295-315, doi:10.2151/jmsj.87A.295.

Matthews, A. J., and H. Y. Y. Li, 2005: Modulation of station rainfall over the western Pacific by the Madden-Julian oscillation. Geophys. Res. Lett., 32, L14827, doi:10.1029/ 2005 GL023595.

— - G. Pickup, S. C. Peatman, P. Clews, and J. Martin, 2013: The effect of the Madden-Julian oscillation on station rainfall and river level in the Fly River system, Papua New Guinea. J. Geophys. Res., 118, 10 926-10 935, doi:10.1002/jgrd.50865.

Nguyen, D.-Q., J. Renwick, and J. McGregor, 2014: Variations of surface temperature and rainfall in Vietnam from 1971 to 2010. Int. J. Climatol., 34, 249-264, doi:10.1002/joc.3684.

Pohl, B., and P. Camberlin, 2006: Influence of the Madden-Julian oscillation on East African rainfall. I: Intraseasonal variability and regional dependency. Quart. J. Roy. Meteor. Soc., 132, 2521-2539, doi:10.1256/qj.05.104.

_ S. Janicot, B. Fontaine, and R. Marteau, 2009: Implication of the Madden-Julian oscillation in the 40-day variability of the West African monsoon. J. Climate, 22, 3769-3785, doi:10.1175/ 2009JCLI2805.1.

Riley, E. M., B. E. Mapes, and S. N. Tulich, 2011: Clouds associated with the Madden-Julian oscillation: A new perspective from CloudSat. J. Atmos. Sci., 68, 3032-3051, doi:10.1175/ JAS-D-11-030.1.

Roca, R., J. Aublanc, P. Chambon, T. Fiolleau, and N. Viltard, 2014: Robust observational quantification of the contribution of mesoscale convective systems to rainfall in the tropics. J. Climate, 27, 4952-4958, doi:10.1175/JCLI-D-13-00628.1.

Roundy, P. E., 2008: Analysis of convectively coupled Kelvin waves in the Indian Ocean MJO. J. Atmos. Sci., 65, 1342-1359, doi:10.1175/2007JAS2345.1.

—, and W. M. Frank, 2004a: A climatology of waves in the equatorial region. J. Atmos. Sci., 61, 2105-2132, doi:10.1175/ 1520-0469(2004)061<2105:ACOWIT>2.0.CO;2.

$\longrightarrow$, and 2 2004b: Effects of low-frequency wave interactions on intraseasonal oscillations. J. Atmos. Sci., 61, 3025-3040, doi:10.1175/JAS-3348.1.

— , and $-2004 \mathrm{c}$ : Applications of a multiple linear regression model to the analysis of relationships between eastward- and westward-moving intraseasonal modes. J. Atmos. Sci., 61, 30413048, doi:10.1175/JAS-3349.1.

Saha, S., and Coauthors, 2014: The NCEP Climate Forecast System version 2. J. Climate, 27, 2185-2208, doi:10.1175/ JCLI-D-12-00823.1.

Schubert, J. J., B. Stevens, and T. Crueger, 2013: Madden-Julian oscillation as simulated by the MPI Earth System Model: Over the last and into the next millennium. J. Adv. Model. Earth Syst., 5, 71-84, doi:10.1029/2012MS000180.

Seo, K.-H., and K.-Y. Kim, 2003: Propagation and initiation mechanisms of the Madden-Julian oscillation. J. Geophys. Res., 108, 4384, doi:10.1029/2002JD002876.

Straub, K. H., and G. N. Kiladis, 2003: Interactions between the boreal summer intraseasonal oscillation and higher-frequency tropical wave activity. Mon. Wea. Rev., 131, 945-960, doi:10.1175/1520-0493(2003)131<0945:IBTBSI >2.0.CO;2.

,-- , and P. E. Ciesielski, 2006: The role of equatorial waves in the onset of the South China Sea summer monsoon and the demise of El Niño during 1998. Dyn. Atmos. Oceans, 42, 216238, doi:10.1016/j.dynatmoce.2006.02.005.

Tong, H. W., J. C. L. Chan, and W. Zhou, 2009: The role of MJO and mid-latitude fronts in the South China Sea summer monsoon onset. Climate Dyn., 33, 827-841, doi:10.1007/ s00382-008-0490-7.

U.S. Energy Information Administration, 2015: International energy statistics. U.S. Department of Energy, accessed 17 December 2015. [Available online at http://www.eia.gov/cfapps/ipdbproject/ iedindex $3 . \mathrm{cfm} ? \mathrm{tid}=2 \&$ pid $=$ alltypes\&aid $=12 \& \mathrm{cid}=\mathrm{VM}$, \&syid $=2008$ \&eyid $=2012$ \&unit $=$ BKWH.]

Ventrice, M. J., M. C. Wheeler, H. H. Hendon, C. J. Schreck III, C. D. Thorncroft, and G. N. Kiladis, 2013: A modified multivariate Madden-Julian oscillation index using velocity potential. Mon. Wea. Rev., 141, 4197-4210, doi:10.1175/ MWR-D-12-00327.1.

Wang, B., 2006: The Asian Monsoon. Environmental Sciences, Springer-Verlag Berlin Heidelberg, 788 pp.

Wheeler, M., and G. N. Kiladis, 1999: Convectively coupled equatorial waves: Analysis of clouds and temperature in the wavenumber-frequency domain. J. Atmos. Sci., 56, 374-399, doi:10.1175/1520-0469(1999)056<0374:CCEWAO > 2.0.CO;2. , and H. H. Hendon, 2004: An all-season real-time multivariate MJO index: Development of an index for monitoring and prediction. Mon. Wea. Rev., 132, 1917-1932, doi:10.1175/ 1520-0493(2004)132<1917:AARMMI>2.0.CO;2.

_ G. N. Kiladis, and P. J. Webster, 2000: Large-scale dynamical fields associated with convectively coupled equatorial waves. J. Atmos. Sci., 57, 613-640, doi:10.1175/1520-0469(2000)057<0613: LSDFAW $>2.0 . \mathrm{CO} ; 2$.

Wu, P., Y. Fukutomi, and J. Matsumoto, 2012: The impact of intraseasonal oscillations in the tropical atmosphere on the formation of extreme central Vietnam precipitation. $S O L A, \mathbf{8}$, 57-60, doi:10.2151/sola.2012-015.

Xavier, P., R. Rahmat, W. K. Cheong, and E. Wallace, 2014: Influence of Madden-Julian oscillation on Southeast Asia rainfall extremes: Observations and predictability. Geophys. Res. Lett., 41, 4406-4412, doi:10.1002/2014GL060241.

Yasunaga, K., and B. Mapes, 2012: Differences between more divergent and more rotational types of convectively coupled equatorial waves. Part II: Composite analysis based on space-time filtering. J. Atmos. Sci., 69, 17-34, doi:10.1175/JAS-D-11-034.1.

Yatagai, A., K. Kamiguchi, O. Arakawa, A. Hamada, N. Yasutomi, and A. Kitoh, 2012: APHRODITE: Constructing a long-term daily gridded precipitation dataset for Asia based on a dense network of rain gauges. Bull. Amer. Meteor. Soc., 93, 14011415, doi:10.1175/BAMS-D-11-00122.1.

Yen, M.-C., T.-C. Chen, H.-L. Hu, R.-Y. Tzeng, D. T. Dinh, T. T. T. Nguyen, and C. J. Wong, 2011: Interannual variation of the fall rainfall in central Vietnam. J. Meteor. Soc. Japan, 89A, 259270, doi:10.2151/jmsj.2011-A16.

Yokoi, S., T. Satomura, and J. Matsumoto, 2007: Climatological characteristics of the intraseasonal variation of precipitation over the Indochina Peninsula. J. Climate, 20, 5301-5315, doi:10.1175/2007JCLI1357.1.

Zhang, C., 2005: Madden-Julian oscillation. Rev. Geophys., 43, RG2003, doi:10.1029/2004RG000158.

—_, and M. Dong, 2004: Seasonality in the Madden-Julian oscillation. J. Climate, 17, 3169-3180, doi:10.1175/ 1520-0442(2004)017<3169:SITMO > 2.0.CO;2.

Zhang, Q., and H. van den Dool, 2012: Relative merit of model improvement versus availability of retrospective forecasts: The case of Climate Forecast System MJO prediction. Wea. Forecasting, 27, 1045-1051, doi:10.1175/WAF-D-11-00133.1.

Zhu, W., T. Li, X. Fu, and J.-J. Luo, 2010: Influence of the Maritime Continent on the boreal summer intraseasonal oscillation J. Meteor. Soc. Japan, 88, 395-407, doi:10.2151/jmsj.2010308. 